Economic Study of Spent Nuclear Fuel Storage and Reprocessing Practices in Russia

Final Report - 09/01/1996 - 08/30/1997

C. E. Singer

G. H. Miley

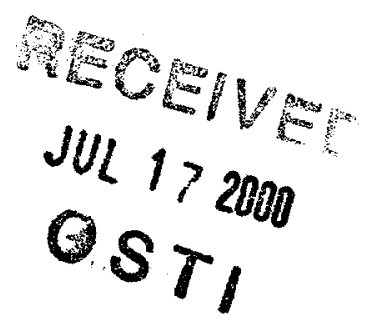

October 1997

Work Performed Under Contract No. DE-FC07-96ID13471

For

U.S. Department of Energy

Assistant Secretary for

Energy Research

Washington, DC

By

University of Illinois at Urbana-Champaign

Urbana, IL 


\section{DISCLAIMER}

This report was prepared as an account of work sponsored by an agency of the United States Government. Neither the United States Government nor any agency thereof, nor any of their employees, make any warranty, express or implied, or assumes any legal liability or responsibility for the accuracy, completeness, or usefulness of any information, apparatus, product, or process disciosed, or represents that its use would not infringe privately owned rights. Reference herein to any specific commercial product, process, or service by trade name, trademark, manufacturer, or otherwise does not necessarily constitute or imply its endorsement, recommendation, or favoring by the United States Government or any agency thereof. The views and opinions of authors expressed herein do not necessarily state or reflect those of the United States Government or any agency thereof. 


\section{DISCLAIMER}

Portions of this document may be illegible in electronic image products. Images are produced from the best available original document. 
DOE/ID/13471

\title{
ECONOMIC STUDY OF SPENT NUCLEAR FUEL STORAGE AND REPROCESSING PRACTICES IN RUSSIA \\ FINAL REPORT \\ 09/01/1996-08/30/1997
}

\author{
C. E. Singer \\ G. H. Miley
}

October 1997

Work Performed Under Contract No. DE-FC07-96ID13471

Prepared for the

U.S. Department of Energy

Assistant Secretary for

Energy Research

Washington, DC

Prepared by

University of Illinois at Urbana-Champaign

Urbana, IL 


\title{
Economic Study of \\ Spent Nuclear Fuel Storage and Reprocessing Practices in Russia
}

Clifford E. Singer and George H. Miley

Co-Principal Investigators

Department of Nuclear Engineering

\author{
Jurgen Wiesmann \\ Department of Economics \\ Madhu Khanna \\ Assistant Professor, Department of Agricultural and Consumer \\ Economics \\ Samuel N. Addy \\ Post-Doctoral Research Associate \\ Department of Agricultural and Consumer Economics \\ and \\ Tod E. Kaspar, Maria Petra, Ji Qiang and Junli Zhang \\ Department of Nuclear Engineering
}




\title{
Economic Study of Spent Nuclear Fuel Storage and Reprocessing Practices in Russia
}

\author{
Clifford E. Singer and George H. Miley \\ Co-Principal Investigators \\ Department of Nuclear Engineering \\ with \\ Jurgen Wiesmann \\ Department of Economics \\ Madhu Khanna \\ Assistant Professor, Department of Agricultural and Consumer Economics \\ Samuel N. Addy \\ Post-Doctoral Research Associate \\ Department of Agricultural and Consumer Economics, \\ and \\ Tod E. Kaspar, Maria Petra, Ji Qiang and Junli Zhang \\ Department of Nuclear Engineering \\ University of Illinois at Urbana-Champaign \\ October 1997
}

This material is based upon work supported by the Department of Energy contract DE-FC07-96ID13471. Any opinions, findings, and conclusions or recommendations expressed in this publication are those of the authors and do not necessarily reflect the views of the Department of Energy. 


\section{Contents}

1 Introduction 1

2 Current Status of Russia's Nuclear Industry 5

2.1 Currently Operating Nuclear Power Plants ............ 5

2.1.1 VVER Reactors . . ............... 6

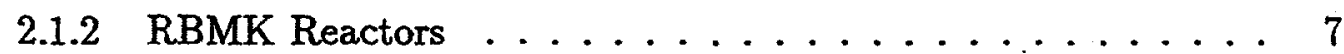

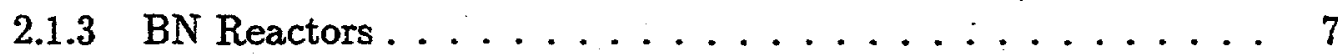

2.2 Supply of Fuel . . . . . . . . . . . . . . . 8

2.3 Spent-Fuel Storage and Disposal . . . . . . . . . . . . 8

2.4 Plans for New Nuclear Power Plants . . . . . . . . . . . . 11

3 The Role of Institutional Factors 14

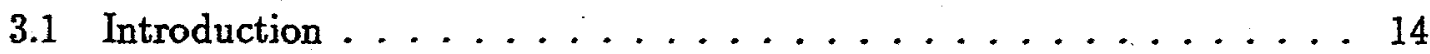

3.2 History of Russia's Nuclear Program . . . . . . . . . . . . 14

3.3 Industrial Organization of Russia's Nuclear Power Industry . . . . . . 16

3.4 Demand Projections and Energy Strategy . . . . . . . . . . 19

3.5 Competitiveness of Nuclear Power . . . . . . . . . . . . . 23

3.6 Shortage of Funds . . . . . . . . . . . . . . . 24

3.7 The Impact of Chernobyl . . . . . . . . . . . . . . . 27

3.8 Employment and Social Issues ................ . . 28

3.9 Exports, R\&D, and National Pride ............... 28

3.10 Prospects of Plutonium Reprocessing . . . . . . . . . . . 29

4 Decision Model for Nuclear-Fuel-Cycle Options 31

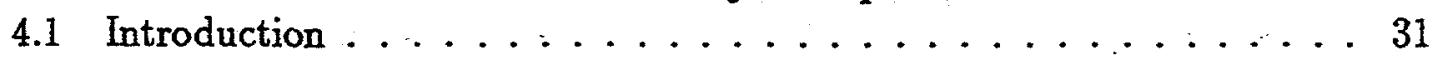

4.2 The Levelised-Lifetime-Cost Approach . . . . . . . . . . . 33

4.3 Components of the Nuclear Fuel Cycle . . . . . . . . . . . . 34

4.4 Cost Developments over Time ................ . . 38

4.5 Regional Cost Differences . . . . . . . . . . . . . 39

4.6 An Example: Comparison of Fuel Cycle Costs for a PWR . . . . . . 41

5 Policy Questions and Quantitative Analysis $\quad 44$

5.1 Funds for Expanding Reprocessing . . . . . . . . . . . . . 47

5.2 Reactor Construction . . . . . . . . . . . . . . 48

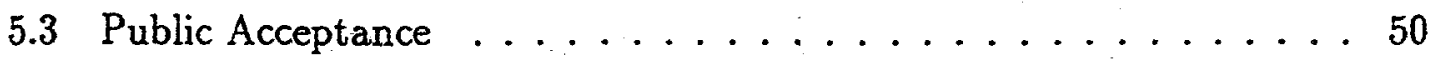

5.4 Regional and Global Energy Markets .............. 50

6 Conclusions $\quad 53$ 


\begin{abstract}
This report describes a study of nuclear power economics in Russia. It addresses political and institutional background factors which constrain Russia's energy choices in the short and intermediate run. In the approach developed here, political and institutional factors might dominate short-term decisions, but the comparative costs of Russia's fuel-cycle options are likely to constrain her long-term energy strategy. To this end, we have also formulated a set of policy questions which should be addressed using a quantitative decision modeling which analyses economic costs for all major components of different fuel cycle options, including the evolution of uranium prices. An international cooperation of very modest scale is recommended for addressing these issues productively.
\end{abstract}

\title{
1 Introduction
}

Recent studies of fuel-cycle economics ${ }^{1}$ have shown that at present spentfuel reprocessing is unlikely to be an economically viable alternative to the use of enriched natural uranium combined with direct disposal of spent fuel. However, the studies indicate that this conclusion could change provided that uranium supply is sufficiently scarce as reflected in high uranium prices and/or shortages of fuel for the existing base of nuclear reactors. It is a goal of this study to establish sound methods for evaluating if and when reprocessing in Russia can become competitive as a commercial operation. Addressing this question requires the development of an analytic framework for examination of a variety of institutional, economic, and technical questions.

Figure 1 illustrates part of the analytical framework employed in this study. It characterizes our understanding of the structural relationships between the key

\footnotetext{
${ }^{2}$ NEA/OECD, 1994.
} 
factors determining the prospects of spent-fuel reprocessing in Russia. A few points are worth discussing here.

1. The study centers on the analysis of energy demand and supply in Russia. However, it recognizes the importance of links with the global energy economy. Specifically, uranium prices are driven by world uranium demand and Russia's option to export fossil fuels clearly affects domestic fuel prices and the competitive position of nuclear power.

2. Demand for energy, electric and non-electric, as well as the demand for fuel exports is driven by domestic and international macroeconomic developments. The most important factors are population growth, increases in GDP, changes in energy efficiency, and the international fuel supply situation.

3. Interfuel Competition: The choice between nuclear, fossil, and hydro-electric power plants is determined by the respective costs of the different technologies, including generation, transportation, and fuel-extraction costs. The competitive position of nuclear power is enhanced due to non-electric uses for fossil fuels as well as opportunities to export them. These alternative uses cause faster depletion of existing fuel reserves and drive up extraction costs.

4. Nuclear Power: The choice between using enriched natural uranium as reactor fuel combined with avoiding near-term reprocessing of the spent fuel versus using promptly reprocessed plutonium and uranium is determined by the respective costs of the two options. Reprocessing can become economically more attractive if the cost of natural uranium rises well above present levels or if, 
in addition to the treatment of domestic spent fuel, the reprocessing facilities can be used for foreign spent fuel or military purposes. Increases in uranium prices may favor reprocessing in the long term, and imports of spent fuel may do so in the shorter term, but military side-benefits of additional reprocessing are definitely a thing of Russia's Cold War past. Natural uranium supply and costs are affected by opportunities to export as well as the release of surplus uranium and plutonium from Russia's military sector.

5. International macroeconomic developments affect the demand for fuel exports from Russia and, thus, the competitiveness of nuclear power versus thermal fossil-fired and hydro-electric plants.

In order to capture the above features of decision making about nuclear energy in Russia, the present study follows a multi-layered approach. The goal is to establish a detailed decision model which identifies the least-cost alternative among different fuel-cycle options in Russia. More specifically, such a model should allow comparison of spent-fuel reprocessing with the costs of long-term storage above and/or underground. Important inputs for the decision model should be provided by a global energy model which incorporates the impact of interfuel substitution and global fuel markets on the development of Russia's nuclear industry. We recognize that decisions about the future of nuclear energy in Russia are to a significant extent determined by a variety of political and institutional factors that interact with other economic considerations. A detailed analysis of the current situation of Russia's nuclear industry as well as certain background factors is included in this report and will be used to identify how these factors constrain Russia's short and 


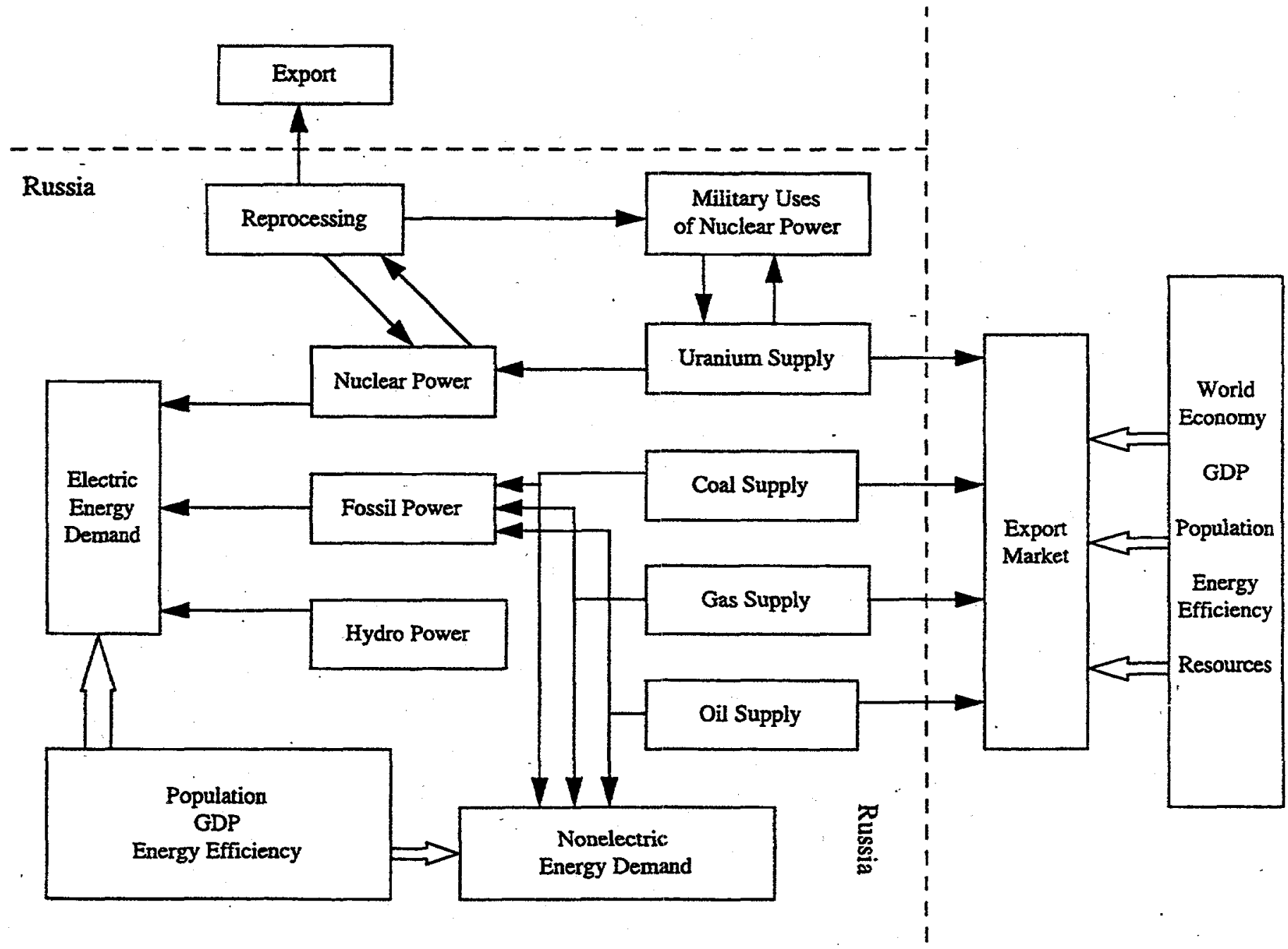

Figure 1: Analytical Framework 
intermediate-term energy choices.

The study's multi-layered approach is reflected in this report. Section 2 provides an update on the status quo in Russia's nuclear industry. Section 3 analyzes how certain institutional background factors influence policy decisions about nuclear energy in Russia in the short and intermediate run. In section 4 an early version of the decision model for Russia's fuel-cycle options is presented, while section 5 gives a summary of policy questions which should be addressed in the context of a regionally disaggregated global energy model. This is followed by concluding remarks and an agenda for future research.

\section{Current Status of Russia's Nuclear Industry}

\subsection{Currently Operating Nuclear Power Plants}

Currently Russia has 29 nuclear power units ${ }^{2}$ at nine sites with a total capacity of approximately $20,000 \mathrm{MW}$ per year. In 1995 , nuclear power plants produced $12.5 \%$ of all electricity in Russia; in the European parts of Russia the share was even higher with $24.9 \%$. Russia's nuclear industry uses a variety of reactor types which are briefly discussed in the following paragraphs ${ }^{3}$ :

\footnotetext{
${ }^{2}$ See Table 1, Appendix 1, and Map 1.

${ }^{3}$ INSC Database.
} 
Table 1. Russia's Currently Operating Nuclear Plants

\begin{tabular}{lll}
\hline Type/Model & Number of Units & MWe(net) \\
\hline RBMK-1000 & 11 & 10,175 \\
VVER-440 & 6 & 3,314 \\
VVER-1000 & 7 & 6,650 \\
BN-600 & 1 & 560 \\
\hline
\end{tabular}

Source: International Nuclear Safety Center (INSC) Database.

\subsubsection{VVER Reactors}

The VVER's are the Soviet counterpart of Western Pressurized Water Reactor (PWR) designs. Like all nuclear units based on light water technology, the Soviet VVER design uses water to cool the reactor and generate steam. Water also acts as a moderator. It slows down the neutrons to increase the chances of fissioning and enhances safety because a water loss slows the nuclear chain reaction. The earliest VVER versions were developed by the Soviets even before 1970 . The most common first-generation design, the VVER-440, model V230, employs six primary coolant loops, each of which is equipped with a horizontal steam generator. The modified Model V213-version of the VVER-440 was a byproduct of the first safety requirements drawn up by the Soviet designers. This model included added emergency core cooling and auxiliary feedwater systems as well as upgraded accident localization systems. The larger VVER-1000 design, developed after 1975, is a four-loop system housed in a containment structure with a spray-type steam suppression system. 


\subsubsection{RBMK Reactors}

RBMK is a Russian acronym meaning "Channelized Large Power Reactor." It achieved notoriety through the Chernobyl accident. This design employs two cooling loops, each of which removes heat from one half of the reactor. Fuel clusters are loaded into individual channels rather than into a single pressure vessel. Saturated steam is formed in the channels and fed to the turbines in a direct cycle. Each loop contains two horizontal-type steam separators interconnected on the water and steam sides. The neutron spectrum is thermalized by a massive graphite moderator block. The plant can be refueled on-line and uses slightly enriched nuclear fuel. There are no RBMK plants operating outside the former Soviet Union.

\subsubsection{BN Reactors}

The Soviets have developed two different types of fast-reactor layouts. The loop type, represented by the $\mathrm{BN}-350$, and the pool type which is common to the BN$600, \mathrm{BN}-800$ and $\mathrm{BN}-1600$ designs. In the loop configuration, the intermediate heat exchangers and pumps of the primary circuit are located outside the reactor vessel. In the pool type, virtually all equipment in the primary circuit is located inside a single vessel. The BN-600 has three parallel heat-transport loops, each of which is equipped with two intermediate heat exchangers and a main circulation pump. Although the $\mathrm{BN}-800$ 's power output is higher than that of a $\mathrm{BN}-600$, most of the reactor components are similar. The $\mathrm{BN}-800$ reactor uses a traditional homogeneous core with mixed uranium-plutonium fuel (MOX) while the $\mathrm{BN}-600$ uses uranium- 
oxide only.

\subsection{Supply of Fuel}

Following the break-up of the Soviet Union in 1991, most fuel-cycle facilities were taken over by the Russian government. However, some sectors of the nuclear fuelproduction complex were left outside Russia. For example, most of the dioxide pellets for fuel assemblies are made in Kazakhstan, and Ukraine supplies zirconium for fuel rods ${ }^{4}$. Russia has extensive uranium resources and one operating uranium processing facility. There are four uranium enrichment plants and two major fuel fabrication facilities, the Elektrostal complex near Moscow and a plant in Novosibirsk. Fuel for VVER-440, RBMK, BN, and GBWR reactors is produced in Elektrostal, while VVER-1000 fuel is fabricated at Novosibirsk. The Ulbinskiy plant in Kazakhstan produces fuel pellets for VVER-1000 and RBMK reactors, which are sent to Novosibirsk and Elektrostal for insertion into the fuel assemblies.

\subsection{Spent-Fuel Storage and Disposal}

Since the beginning of her nuclear programs, Russia has given priority to the reprocessing option, partly for military reasons. Originally, reprocessing facilities near Chelyabinsk, Krasnoyarsk and Tomsk ${ }^{5}$ were used to separate weapons-grade plutonium ${ }^{6}$. While the facilities at Krasnoyarsk and Tomsk continue to be used for military purposes, the RT-1 plant in Chelyabinsk began reprocessing commercial re-

\footnotetext{
${ }^{4}$ See Appendix 2.

${ }^{5}$ See Map 2.

${ }^{6}$ Pearson and Nadler, 1996.
} 
actor fuel in 1976. Currently, spent fuel from Russia's VVER-440 reactors and her fast breeder is sent there. The recycled uranium is used to produce fuel for RBMK reactors. Spent fuel from VVER-1000 plants is stored either at the plant sites or transported to a facility near Krasnoyarsk, where a second commercial reprocessing plant, RT-2, is under construction. Work on the reprocessing facility has been delayed because of funding difficulties. At present it is only about $25 \%$ complete, and thus, RT-2 may not be operational by its target date of 2005 .

Spent fuel from Russia's RBMK's is not processed because it is considered too expensive to do so. Reprocessing of the RBMK fuel is unattractive due to the low content of fissile plutonium in the fuel. Instead the fuel is stored at reactor plant sites. Construction of a centralized long-term dry storage facility for spent RBMK fuel was planned, but has reportedly been postponed. As a result, on-site storage at RBMK plants is being expanded. The French company SGN/Reseau Aursys has been awarded a contract to build storage facilities at the Kursk and Smolensk plants. According to the Ministry of Atomic Energy (MinAtom), Russia's nuclear plants have sufficient on-site storage for ten more years of operation. Similarly, the Krasnoyarsk facility is projected to be full by 2010 , even if VVER-1000 plants increase their on-site storage capacity for spent fuel ${ }^{7}$. The ministry is said to be considering the possibility of using deep underground caverns near Chelyabinsk as a final repository for spent fuel.

In addition to spent fuel from its own VVER-440 reactors, Russia has accepted spent fuel from VVER-440 reactors in Eastern Europe for reprocessing. For

\footnotetext{
${ }^{7}$ INSC Database.
} 
a couple of years, the status of spent-fuel imports has been the subject of intense debate between Russia's government and her legislature. In May 1994, the Russian government issued a decree concerning the environmental protection action plan for 1994-1995 which prohibited the import of radioactive waste. However, by defining spent fuel as a raw material, Russia's Ministry of Atomic Energy has continued to accept spent fuel from other countries. In June 1994, the lower house of Russia's parliament, the Duma, approved a Draft Law on Handling Radioactive Wastes which completely prohibited the import of nuclear waste. Finally, in September 1995, the Russian government issued a decree stating that all radioactive waste received by Russia must be returned to its country of origin after no more than 20 years. Under this decree, countries shipping spent fuel to Russia would, after 20 years, presumably either have to take back the fuel if Russia were unable to reprocess it, or accept the waste if Russia did reprocess the spent fuel. The Russian government also approved new rules on reprocessing that would allow spent fuel from foreign reactors to be stored at Krasnoyarsk until RT-2 is completed. Fees from such storage could be used for the construction of RT-2. However, local opposition to the import of foreign fuel reportedly led to a collapse of talks with Germany and Switzerland on the shipment of spent fuel to Krasnoyarsk.

As far as the transportation of spent fuel is concerned, the VVER-440, VVER-1000 and naval fuel are shipped in TK-6, TK-10, TK-13, or TK-18 casks. The fuel can be transported by rail ${ }^{8}$. When a rail shipment is made, it consists of 4-10 cars each carrying a cask, one car escort, and two cars with protection

\footnotetext{
${ }^{8}$ Pearson and Nadler. 1996
} 
forces. One problem with such transport is the relatively long distance (up to 3,000 miles) between reactor sites, the reprocessing facility at Chelyabinsk, and the VVER1000 storage facility at Krasnoyarsk. No transportation problem arises for RBMK fuel, since this is stored on-site at the reactor.

\subsection{Plans for New Nuclear Power Plants}

In May 1994, the Ministry of Atomic Energy (Minatom) issued a draft strategy for nuclear energy through the year 2010. The following reactor types are planned for construction ${ }^{9}$ :

1) A 1000-MW VVER with enhanced safety features (NP-1000). 2) A 1100MW VVER with enhanced safety features (NP-1100). 3) A 640-MW VVER with enhanced safety features (NP-500). 4) A 640-MW VVER with passive safety features (VPBER-600). 5) A 800-MW fast breeder reactor (BN-800). 6) A 800-MW channeltype reactor with enhanced safety features (MKER-800). Sosnovvy Bor (Leningrad) has been chosen as the site for the first NP-500, Novovoronezh for the first NP-1000 and NP-1100, and the Primorskaya and Kostroma sites for the first VPBERs. The NP-500 is also planned for construction at the Kola site. Completion of the first three units is envisioned by 2003 , when the first two existing plants, both VVER$440 / V 230$ s, are due for decommissioning.

As discussed in more detail below, the difficulty of securing financing for capital-intensive projects in Russia suggests that it may be difficult to realize all reactor construction plans on the schedule presently envisioned. Moreover, nuclear

\footnotetext{
${ }^{9}$ INSC Database.
} 
energy faces stiff competition from fossil fuels in and around Russia, particularly if adequate natural gas pipelines are eventually built to service needs presently met by nuclear electric plants. Figure 2 illustrates what would happen to nuclear power capacity if the two factors combined would limit future power plant construction to what is currently planned or under construction. It was assumed that completion dates for plants planned and on order would be delayed by an amount of time equal to the average difference between initially targeted and presently projected completion dates for plants currently listed as "under construction." ${ }^{10}$ Moreover, plants are assumed to be decommissioned after $T$ years after entry into industrial service, with

$$
\left.T=25+15\left[1-\exp ^{(} P_{G W e} / 0.4\right)\right]^{11}
$$

The results shown in Figure 2 should be viewed as posing a question rather than providing an answer. The question is: at what point may economic recovery in Russia and eventual depletion of fossil fuel resources bring to bear pressures sufficiently strong to increase installed nuclear capacity above the levels for the delayed-construction and eventual-phase-out scenario shown in Figure 2? This is an important question which must eventually be answered in order to understand the likely eventual fate of Russian plutonium stocks. We shall return briefly to the question of how to approach closure on this question below, after first addressing institutional issues and fuel cycle options.

\footnotetext{
${ }^{10}$ The data for this exercise was obtained from the Commissariat a l'Energie Atomique. See CEA.

${ }^{11}$ This functional form allows for a 40 year life for large plants, and for the observation that smaller plants tend to be decommissioned after a somewhat shorter operating life than larger ones, on economic grounds.
} 


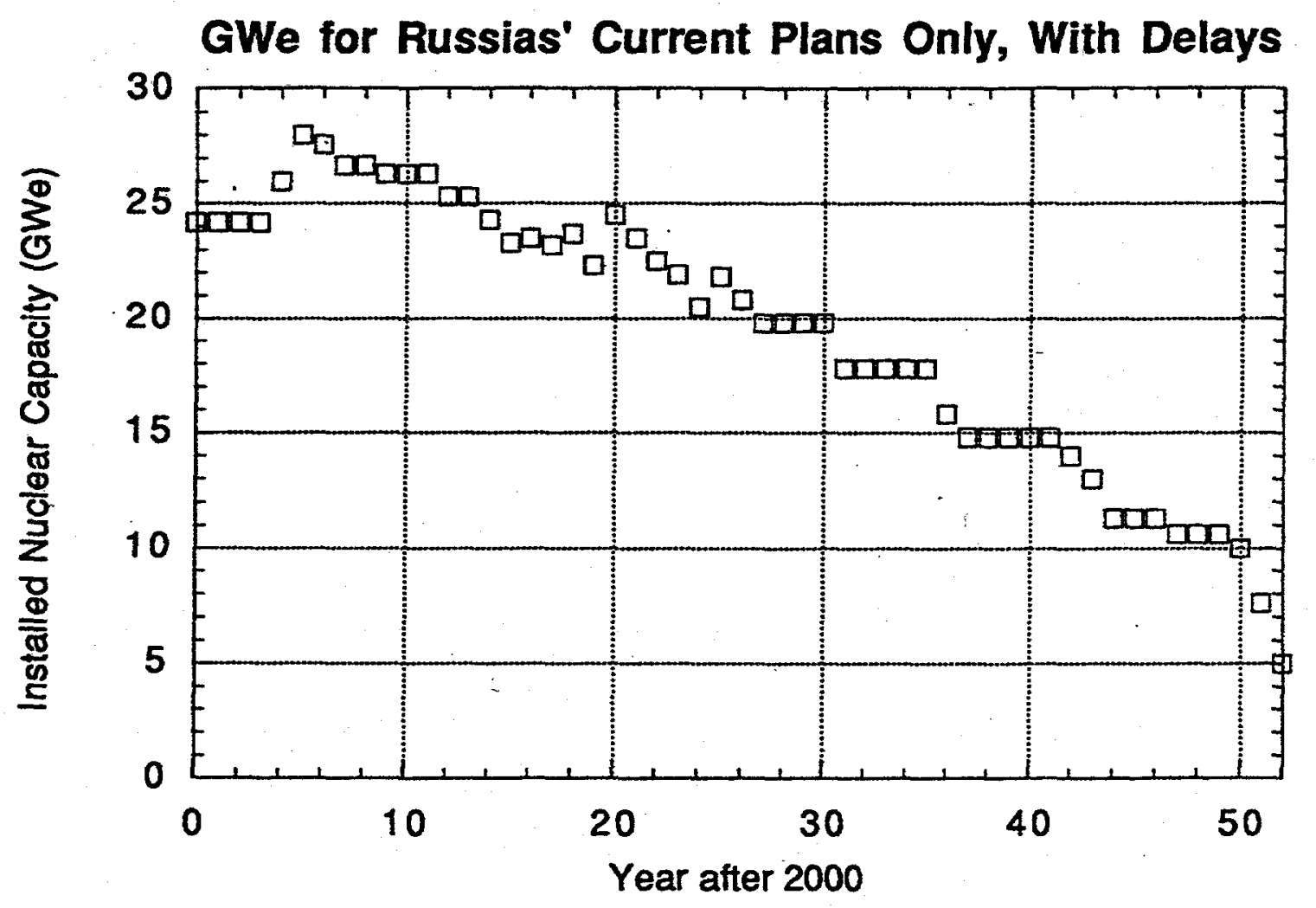

Figure 2: Projected nuclear generating capacity in Russia 


\section{The Role of Institutional Factors}

\subsection{Introduction}

Decision making about the future of nuclear power involves a variety of institutional factors, which constrain choices decision makers can opt for in pursuing least-cost solutions. In most nuclear countries a variety of political, historical, cultural, economic, and military background factors have shaped their respective nuclear programs. Russia, a country in transition from a planned to a market economy and from socialist one-party rule to a vibrant and frequently chaotic democracy, is certainly no exception. Contradictions between the old and new system are unavoidable and have caused friction in Russia's economic and political life. Recent rapid inflation and the deep recession Russia is currently experiencing have caused additional disruptions. It is, therefore, the purpose of this section to explore how certain background factors, such as the organizational structure of Russia's power industry and the interests of her nuclear industry, constrain Russia's energy choices and influence the prospects for nuclear power and plutonium reprocessing in the region ${ }^{12}$.

\subsection{History of Russia's Nuclear Program}

In 1920, Lenin himself stated that "Communism is Soviet power plus the electrification of the entire country" ${ }^{13}$. Since the early days of the Soviet Union, electric power has been considered a key link and driving force for industrial expansion.

\footnotetext{
${ }^{12}$ Similar considerations have been raised in studies for other regions. For example, Skolnikoff, Suzuki, and Oye emphasize the role political and cultural background factors play in Japan's adherence to her plutonium programs. See Skolnikoff, Suzuki, and Oye, 1995.

${ }^{13}$ Cited after Ebel, 1994, p.65.
} 
Table 2. Nuclear Power Generation in the Soviet Union 1970-1991 (in billion $\mathrm{kWh}$ ).

\begin{tabular}{lllllll}
\hline Year & 1970 & 1975 & 1980 & 1985 & 1990 & 1991 \\
\hline Nuclear Power & 3.5 & 20.2 & 72.9 & 167.4 & 212.6 & 208.0 \\
Total Power & 740.9 & 1038.6 & 1293.9 & 1544.1 & 1721.7 & 1687.0 \\
\% Nuclear & 0.47 & 1.94 & 5.63 & 10.84 & 12.35 & 12.33 \\
\hline
\end{tabular}

Source: CIA. 1990, Table 13. Ebel. 1995, p.67,72.

After World War II the Soviet Union embraced the seemingly unlimited promise of nuclear power and created one of the world's most ambitious nuclear programs. Nuclear activities were organized under the military-industrial complex with the dual objectives of building nuclear weapons and providing large amounts of cheap electricity. Reactors were mostly built in the densely populated Western parts of the Soviet Union, especially Ukraine, Lithuania, and European Russia which are far from the rich deposits of coal, oil, and natural gas that can be found east of the Urals. Having launched a first prototype plant as early as 1954, the Soviets began large-scale construction of nuclear reactors in the early 1970's. As shown in Table 2, the share of nuclear power increased from only $0.5 \%$ in 1970 to almost $11 \%$ in 1985 .

The phenomenal growth of nuclear power generation came to a halt in 1986 with the explosion of the Chernobyl-4 plant. With a whole nation suddenly losing confidence in nuclear power, the construction of additional nuclear plants was slowed, suspended, or canceled. Instead of reaching the ambitious goal of 390 billion $\mathrm{kWh}$ per year by 1990 , production grew only slightly from 167 billion $\mathrm{kWh}$ in 1985 to 212 billion $\mathrm{kWh}$ in 1990. 
Table 3. Nuclear Power Generation in the Russian Federation 1990-1995 (in billion $\mathrm{kWh}$ ).

\begin{tabular}{lllllllll}
\hline Year & 1980 & 1985 & 1990 & 1991 & 1992 & 1993 & 1994 & 1995 \\
\hline Nuclear Power & 54.0 & 99.0 & 118.3 & 120.0 & 119.5 & 120.0 & 98.0 & 100.0 \\
Total Power & 805.0 & 703.0 & 1082.2 & 1068.2 & 1008.5 & 957.0 & 876.0 & 850.0 \\
\% Nuclear & 6.71 & 14.08 & 10.93 & 11.23 & 11.85 & 12.54 & 11.19 & 11.76 \\
\hline
\end{tabular}

Source: IEA/OECD. 1995, p.220. World Bank. 1993, p.506.

In 1991, when the Soviet Union was broken up, Russia's share accounted for more than $55 \%$ of total nuclear power capacity. Since then there has been stagnation in the nuclear sector, as shown by Table 3. However, despite a marked decline in GDP, industrial output, and overall electricity demand, nuclear power production has been remarkably stable at least through 1993, while fossil-fired plants showed á strong decline. Since 1993 however, nuclear power generation has been adversely affected by the lack of operating funds.

\subsection{Industrial Organization of Russia's Nuclear Power In- dustry}

The nuclear sector was in a very special position because it has been effectively shielded from the impacts of Perestroika, the turbulence following the break-up of the Soviet Union, and some of the market reforms of the last years ${ }^{14}$. In 1991 Russia not only took over the nuclear power plants in her territory, but also an almost complete collection of fuel-cycle facilities, all important research institutes, as well

\footnotetext{
${ }^{14}$ IEA/OECD. 1995, p.225.
} 
as the organizational structure and the personnel of the former Soviet Ministry for Atomic Power and Industry (MAPI). The nuclear sector is, thus, one of the most socialist but also one of the least disrupted in Russia.

Since 1992 there have been cautious steps towards transforming the nuclear power sector into a commercial operation. To operate Russia's nuclear plants the joint-stock company Rosenergoatom (REA) was created. Rosenergoatom is responsible for operating all Russian nuclear power plants, with the sole exception of the Leningrad (Sosnovvy Bor) plant. Its responsibilities include plant maintenance and repair, technical support as well as operations and emergency planning ${ }^{15}$. However, REA is still controlled by the Ministry of Atomic Energy (MinAtom) ${ }^{16}$.

REA sells the electricity it produces to the Unified Electric Power System of Russia (RAO-EES), a joint-stock company under the Ministry of Energy, which operates the interregional network, organizes the wholesale electricity market, and operates most large fossil fuel and hydro-electric plants. RAO-EES also has a controlling share in 72 regional distribution companies (energos) which operate the remaining, mostly smaller, power plants. RAO-EES is financed through a service fee which is included in the price of electricity ${ }^{17}$.

This structure implies a strict separation of nuclear and non-nuclear power, which causes problems for integrated resource planning. It makes it very difficult to consider replacement of nuclear capacity by fossil-fired plants or vice versa. It

\footnotetext{
${ }^{15}$ INSC Database.

${ }^{16}$ See Figure 3 for an organizational chart of Russia's nuclear sector. The chart is taken from IEA/OECD. 1995, p.226.

${ }^{17}$ IEA/OECD. 1994b, p.199.
} 


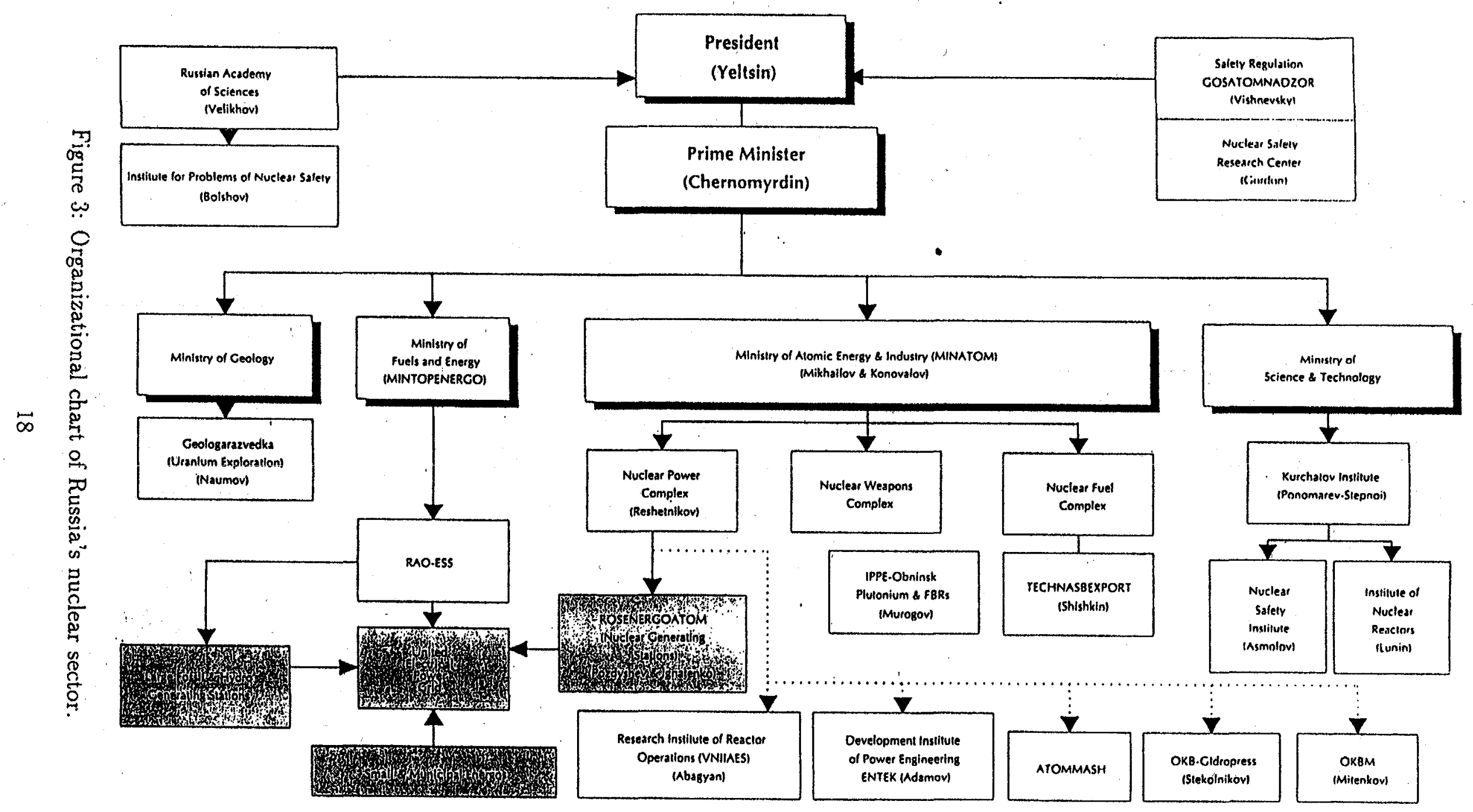


also does not encourage REA or RAO-EES to thoroughly compare the costs and benefits of the nuclear versus the non-nuclear option. In effect, it might cause them to protect their own turf and hold on to their present market share or generating capacity without regard to least-cost solutions.

An additional problem results from the peculiar situation that REA's revenues and investment funds are largely controlled by RAO-EES, which to a certain extent is a major competitor. By withholding payments to the nuclear sector, RAOEES can fund its own fossil-fuel projects while stifling investment in new nuclear reactors. This problem will be discussed later in connection with the general nonpayment crisis in Russia's energy sector.

Gosatomnadzor (GAN), an agency directly under the President, is responsible for regulatory oversight of Russia's civilian nuclear power plants ${ }^{18}$. GAN licenses all civilian facilities that use radioactive materials, develops rules and standards governing the safe use of these materials, including nuclear power plants. GAN is also charged with approving the design and construction of all nuclear plants.

\subsection{Demand Projections and Energy Strategy}

There is great uncertainty about Russia's future demand for electricity due to the following factors:

1. Uncertainty about Russia's macroeconomic development, especially about when the bottom of the current recession will be reached and how smooth and fast

\footnotetext{
${ }^{18}$ The Ministry of Defense is responsible for all military nuclear facilities.
} 
a recovery will follow.

2. Uncertainty about the future industrial structure of Russia's economy, especially the future role of her heavy industry.

3. Uncertainty about the sequence and speed of economic reforms.

4. Uncertainty about future pricing policies. Ultimately, Russia's energy prices can be expected to reach world market levels.

5. Uncertainty about Russia's potential to achieve energy efficiency improvements. The demand reduction potential has been estimated as up to 390 billion $\mathrm{kWh}$, or about $40 \%$ of current consumption ${ }^{19}$. Efficiency improvements certainly depend on the speed of energy price reform, the introduction of electricity meters for all consumer groups, and the enforcement of payments owed to the energy sector.

6. Uncertainty about Russia's changing load structure. Russia now has a very flat load pattern due to the large share of industrial demand for electricity. With increasing residential demand this load pattern is expected to worsen unless demand management methods can be successfully employed.

As a consequence, forecasts of future electricity demand have differed widely. As Table 4 shows, the Russian government's forecast for nuclear power generation in 2010 exceeds the IEA/World Bank scenario by over $18 \%$, although the forecasts were made in the same year. While the IEA/World Bank predicted only a $14 \%$ increase

\footnotetext{
${ }^{19}$ IEA/OECD. 1995, p.209.
} 
Table 4. Projected Electricity Demand (in billion $\mathrm{kWh}$ ).

\begin{tabular}{lcccccc}
\hline Year & 1990 & 1994 & 1995 & 2000 & 2005 & 2010 \\
\hline actual & 1082 & 876 & & & & \\
IEA Scenario 95 & & & 850 & 950 & 1080 & 1200 \\
IEA/World Bank 92-93 & & & 833 & 833 & 975 & 1235 \\
Russian Govt. 92-93 & & & 1060 & 1169 & 1298 & 1461 \\
\hline
\end{tabular}

Source: IEA/OECD. 1995, p.206.

over the 1990-level of nuclear power production by 2010 , the Russian government predicted a $35 \%$ increase.

Besides adding new capacity to meet increased energy demand, Russia has a large number of old power plants which are due for retirement. Table 5 illustrates the age structure of Russia's power plants. From 1995-2000, it is estimated that $40 \mathrm{GW}$ of capacity, mostly fossil-fired plants, will have reached their design age ${ }^{20}$ and by 2010 , up to $50 \%$ of present nuclear capacity are due for retirement, i.e. 15 reactors with a total of $7,083 \mathrm{MW}^{21}$.

Most of the replacement for non-nuclear plants will be in the form of combined-cycle natural gas plants. However, Russia would eventually like to increase the share of nuclear power in order to conserve more of the limited natural gas resources for the lucrative export market. Natural gas is a very valuable export commodity. In 1993 its export price exceeded the domestic wholesale price about

\footnotetext{
${ }^{20}$ IEA/OECD. 1995, p.200.

${ }^{21}$ IEA/OECD. 1995, p.219, 220.
} 
Table 5. Age Distribution of Russian Power Plants, 1992 (in GW).

\begin{tabular}{llllll}
\hline Age & All fuels & Nuclear & Hydro & Fossil & Percentage \\
\hline All ages & 194.4 & 21.2 & 39.5 & 133.7 & 100.0 \\
Over 43 years & 5.2 & 0.0 & 0.9 & 4.3 & 2.7 \\
33-43 years & 22.8 & 0.0 & 8.4 & 14.4 & 11.7 \\
23-33 years & 55.2 & 0.9 & 13.2 & 41.1 & 28.4 \\
13-23 years & 62.3 & 8.4 & 10.0 & 43.9 & 32.0 \\
less than 13 years & 48.9 & 11.9 & 7.0 & 30.0 & 25.2 \\
percentage & 100.0 & 10.9 & 20.3 & 68.8 & \\
\hline
\end{tabular}

Source: IEA/OECD. 1994a.

nine times ${ }^{22}$. Since then, the real exchange rate of Russia, the ratio of the interbank rate and the purchasing power parity, has rapidly increased and narrowed the difference ${ }^{23}$, but exporting natural gas still remains very attractive.

Based on the above demands for new and replaced capacity, Russia's energy strategy for the nuclear sector is divided into three phases ${ }^{24}$ :

Until 2000: Renovation. The goals are to modernize existing nuclear reactors, replace reactors which have reached their design life, and complete the development of enhanced-safety reactors and fast-breeder reactors.

2000-2010: Nuclear capacity is supposed to double with the completion of 3 or 4 breeder reactors and the introduction of fourth-generation (enhancedsafety) nuclear plants. The first-generation plants (RBMK, VVER-440) will finally

\footnotetext{
${ }^{22}$ IEA/OECD, 1994b, p.91.

${ }^{23}$ PlanEcon. 1997, p.22.

${ }^{24}$ See Interagency Commission. 1995.
} 
be decommissioned ${ }^{25}$.

After 2010: The large-scale expansion of nuclear power generation is envisioned. In addition to plant renovation and new construction, major investments are necessary to prevent environmental damage from on-site storage of nuclear wastes, correct unorthodox disposal techniques such as sea dumping and injection of liquid radioactive wastes, and improve safety at the high-risk first-generation nuclear reactors. Russia's nuclear industry, therefore, has a sizable need for capital to finance their activities both in the intermediate and long run.

\subsection{Competitiveness of Nuclear Power}

Initial estimates show that generation costs for nuclear power plants are similar to fossil-fired plants, in June 1994 the average cost was reported to be 30-60 rubles $/ \mathrm{kWh}$ for both options. Hydro-electric power was considerably cheaper at $7-11$ rubles $/ \mathrm{kWh}^{26}$, but its use is naturally restricted to certain areas. Because of Russia's vast size and its uneven distribution of resources and population, regional differences have a major impact on relative costs and the location of nuclear power plants. All but $600 \mathrm{MW}(3 \%)$ of nuclear generating capacity is in the Northwest (27\%), Central (51\%), and Middle Volga (19\%) regions ${ }^{27}$. In the Northwest, nuclear power accounts for $40 \%$ of generated electricity ${ }^{28}$, and in the Central and Middle

\footnotetext{
${ }^{25}$ NEI. 1995, p.71.

${ }^{26}$ IEA/OECD. 1995, p.208. A conversion to US dollar is not very meaningful, due to the very high Russian inflation rate and the rapidly changing exchange rate.

${ }^{27}$ DOE/EIA. 1995, p.88.

${ }^{28}$ IEA/OECD. 1995, p.212.
} 
Table 6. Comparison of Power Generation Costs for Fossil and Nuclear Plants (in $\mathrm{kop} / \mathrm{kWh}=0.01$ rubles $/ \mathrm{kWh}$ )

\begin{tabular}{cccc}
\hline Year & Fossil Fuel Plants & Nuclear Power Plants & Nuclear/Fossil \\
\hline 1988 & 1.24 & 1.04 & 0.84 \\
1989 & 1.26 & 1.04 & 0.83 \\
1990 & 1.31 & 1.11 & 0.85 \\
1991 & 1.33 & 1.99 & 1.50 \\
\hline
\end{tabular}

Source: Russian Academy of Sciences. 1992. Cited after NEA and IEA/OECD. 1993, p.126.

Volga regions for approximately $20 \%{ }^{29}$. All three regions have in common that they are densely populated and lie far from the rich deposits of natural gas and coal in the Eastern parts of the country. Under these conditions nuclear energy is very competitive with fossil-fired power generation. Future developments might favor nuclear power when considering that prices for natural gas, which were kept artificially low in the past, might soon reach the much higher world market levels.

On the other hand, nuclear power generation costs have sharply increased due to higher nuclear safety standards as is shown in Table 6. Even stricter regulations can be expected in the future, so that unit costs could double over the next decade.

\subsection{Shortage of Funds}

The substantial investment needs discussed above are confronted by a nuclear industry which is in a deep financial crisis. The causes are manifold.

\footnotetext{
${ }^{29}$ Calculated under the assumption that a region's generated nuclear power is proportional to its capacity.
} 
Investment financing for the nuclear sector used to be provided by the federal government. Nuclear programs received preferential funding, better materials, better-trained workers, and a stronger $R \& D$ base than other sectors of the economy ${ }^{30}$. However, allocations from the federal budget have ceased and the nuclear industry is now responsible for raising its own funds, predominantly via depreciation allowances and an investment fund that is collected as a $4 \%$ surcharge on electricity prices.

Energy prices are set by regional energy commissions, which are dominated by local governments: While they are supposed to follow procedures set by the Federal Energy Commission, they have considerable discretion to take account of local conditions ${ }^{31}$. As a result, electricity prices have varied widely, and there is evidence that the regional energy commissions systematically underprice electricity. For example, many regions do not collect contributions to the investment fund and do not allow full cost recovery for electricity producers ${ }^{32}$.

There is a severe non-payment crisis all over the fuel and energy sector. $50 \%$ of non-payments are owed by state-owned organizations ${ }^{33}$. In this general climate of soft-budget constraints and non-payment, RAO-EES, which buys all generated nuclear power, essentially controls the investment funds for the nuclear sector. It then has to choose between paying the nuclear sector and conserving funds for its own fossil projects. As noted above, the nuclear industry thus finds itself in a

\footnotetext{
${ }^{30}$ IEA/OECD. 1995, p.217.

${ }^{31}$ IEA/OECD. 1995, p.199.

${ }^{32}$ IEA/OECD. 1995, p.202.

${ }^{33}$ IEA/OECD. 1995, p.204.
} 
situation where a competitor controls its investment funds ${ }^{34}$.

There is a thorough lack of private and foreign investment. The intransparent financial situation of power plants makes private involvement in Russia's power industry an unduly risky undertaking ${ }^{35}$.

Russia owns the world's largest inventory of enriched uranium, a stock able to fuel Russia's current base of reactors for 90 years without any further mining and worth 10-20 billion US dollars. However, Russia is currently prevented from fully utilizing this valuable asset, since Western countries have invoked anti-dumping provisions to limit the impact of Russian uranium on world markets and protect their own uranium supply industries ${ }^{36}$.

Effects of the financial crisis in Russia's nuclear industry are widespread and very visible. The completion of new plants under construction has been postponed, and remaining investment activity has shifted to the reconstruction of existing plants ${ }^{37}$. The shortage of operating funds has resulted in shortages of spare parts, operating supplies, and even fuel. Wages have been paid irregularly and the apparent decrease in workers' discipline and maintenance activities have not only lead to lower load factors (since 1994) but also heightened concerns about the safety of Russia's reactors ${ }^{38}$. Moreover, the non-payment problem has spread to Russia's fuel-cycle facilities and caused disruptions to the extent that a shortage of fuel pellets has occurred. Waste management has been affected to the extent that the practice

\footnotetext{
${ }^{34}$ IEA/OECD. 1995, p.224.

${ }^{35}$ IEA/OECD. 1995 , p.203.

${ }^{36} \mathrm{IEA} / \mathrm{OECD} .1995$, p.233.

${ }^{37}$ IEA/OECD: 1995 , p.213.

${ }^{38}$ IEA/OECD. 1995, p.218 and NEI. 1995, p.71.
} 
of on-site storage has been extended, while work on the new RT-2 reprocessing facility has been interrupted. The present on-site storage facilities will be filled within a couple of years, as will be the site near the new RT-2 plant. Environmental pollution at the present storage sites is already extremely severe. Finally, without sufficient facilities for permanent or temporary storage, Russia might find itself in a situation where it is forced into reprocessing to buy more time. While this expedient exchanges the problem of establishing spent fuel storage for the construction of storage for reprocessing wastes, it may still be adopted if financing arrangements develop which preclude the former but allow the latter.

\subsection{The Impact of Chernobyl}

Besides the shortage of funds, Russia's nuclear industry is fighting severe acceptance problems for new nuclear power projects. The experience of the Chernobyl accident has resulted in considerable local opposition to new nuclear projects and has caused the cancellation and delay of a large number of projects. Among the population there are serious concerns about the Russian government's ability to guarantee the safety of its reactors. Confidence in unlimited progress has been shattered and there is little trust in the government as an efficient and able institution. Against this background, it would seem that nuclear safety, although expensive, is the key to the future for Russia's nuclear industry. But even with safer new reactor designs, the expansion of nuclear power will have to be gradual in order to overcome local opposition and regain the confidence of the populace. 


\subsection{Employment and Social Issues}

When MinAtom was created in January 1992, it took over a staff of more than a million employees, nearly $2 \%$ of the country's work force ${ }^{39}$. With the employees it also took over the responsibility of providing employment and social services for them. Much of Russia's nuclear industry was located in closed and often secret cities with little.if any alternative employment opportunities, so that closing existing plants and fuel-cycle facilities carries the danger of provoking social unrest. Since nuclear and non-nuclear activities are strictly separated, there is little prospect that employment can be shifted from the nuclear to the non-nuclear power sector or vice versa. Rather, it is likely that MinAtom and RAO-EES will try to protect or expand their own market share. Expansion of nuclear capacity would seem the only means to further guarantee employment while reducing staff in existing operations to improve competitiveness ${ }^{40}$.

\subsection{Exports, R\&D, and National Pride}

After the break-up of the Soviet Union, Russia managed to retain the expertise and facilities of the high-powered research institutions which had driven the Soviet Union's nuclear programs for decades. Russia, thus, successfully claimed the position as one of the world leaders in nuclear technology. It has developed enhanced- safety nuclear plants that meet high safety standards and is leading in the development of space and fast-breeder reactors. Hence, nuclear technology appears as the one area

\footnotetext{
${ }^{39}$ IEA/OECD. 1995, p.217.

${ }^{40}$ IEA/OECD. 1995, p.219.
} 
of high-tech where Russia may compete successfully in world markets, a position she is unlikely to give it up easily.

Nuclear technology has also emerged as a major export market for Russia. Currently she is cooperating with Armenia, Belarus, China, and Iran on the construction and operation of nuclear power plants ${ }^{41}$. Additional collaborations with countries in Eastern Europe, India, Czech, and Kazakhstan involve either the construction of fast- breeder reactors or plutonium reprocessing in Russia. By commercializing reprocessing services, Russia could capitalize on the desire of other countries to avoid the issue of final disposal as long as possible ${ }^{42}$. Nuclear technology in general, and reprocessing and conceivably breeder reactors in particular, therefore, appear to be promising export markets for Russia. This represents an opportunity that Russia will not discard easily.

\subsection{Prospects of Plutonium Reprocessing}

The reprocessing of spent fuel has been an integral part of Russia's and the Soviet Union's energy strategy since the introduction of nuclear power. As early as 1973 they operated the first fast-breeder reactor. The motivations for a closed fuel cycle have been similar to other countries: increasing the size of available energy resources, reducing the amount of plutonium and radioactive wastes, reducing traditional air pollution, and military spin-offs. However, in a time when uranium stockpiles are abundant, when other countries reject reprocessing due to poor economics and concerns about nuclear proliferation, when environmental effects of on-site storage and

\footnotetext{
${ }^{41}$ NEI.1995, p.79.

42 IEA/OECD. 1995, p.239 and NEI. 1995.
} 
unconventional disposal techniques most likely outweigh effects of traditional air pollution, and when the military's interest is moving away from nuclear power, these traditional rationales for reprocessing are no longer very convincing.

A look at certain background factors particular to Russia is again illuminating. As mentioned above, fast-breeder technology, reprocessing services, and perhaps mixed-oxide fuel (MOX) plants can eventually become lucrative export items, depending on nuclear power developments worldwide. In order to take advantage of such export opportunities Russia has to maintain her R\&D advantage and development capacity in these areas. This puts particular emphasis on maintaining the long-term reprocessing option, while neglecting short-term cost effectiveness.

Russia is already operating a commercial reprocessing plant, the RT-1 in Chelyabinsk, which uses spent fuel from VVER-440 reactors and has an annual capacity 2.6 tons plutonium. A second plant, the RT-2 in Krasnoyarsk, is under construction. After completion it can use spent fuel from VVER-1000 reactors as well as foreign nuclear power plants and will have an annual capacity of 20 tons plutonium. Currently construction on the project is halted because of financial difficulties ${ }^{43}$. If completed, the large capital investments sunk into the project would lock Russia into the long-term operation of the reprocessing plant in order to recover the invested funds.

Russia's nuclear industry has been trying to negotiate agreements with other countries to reprocess their nuclear waste at the RT-2 plant in Krasnoyarsk. Such agreements would entail storing foreign spent fuel at the site of the to-be-constructed

\footnotetext{
${ }^{43}$ IEA/OECD. 1995, p.234 and NEI. 1995, p.78.
} 
reprocessing plant. Russia would charge a reprocessing fee, use the recycled plutonium and uranium, and send the radioactive waste back to the country of origin ${ }^{44}$. These plans have become a bone of contention between the Russian government which supports them and the legislature which opposes them ${ }^{45}$. Depending on the outcome, reprocessing agreements with foreign countries could compel Russia to finally complete the reprocessing plant and to pursue a long-term reprocessing strategy.

\section{Decision Model for Nuclear-Fuel-Cycle Options}

\subsection{Introduction}

The nuclear fuel cycle is a multi-stage process, covering activities ranging from the mining of uranium ore; over the conversion, fabrication, and enrichment of uranium; to spent-fuel processing and the final disposal of nuclear wastes. Figure 4 illustrates the different stages of this complex process and draws attention to two options for spent-fuel handling: direct disposal and reprocessing. While the direct disposal process can be subdivided into transportation, interim storage, encapsulation and final disposal, the reprocessing option mainly consists of transportation, reprocessing, and the final disposal of high-level radioactive wastes.

The study described here employs the levelised-cost method in order to evaluate the relative costs of the two fuel-cycle options based on a detailed cost analysis for all components of the fuel cycle based on data for a reference French

\footnotetext{
${ }^{44}$ Reuter. September 5, 1995.

${ }^{45}$ Reuter. September 5, 1995 and Interfax. February 2, 1995.
} 
Phase

Cost comoonent

1.

Front-end

u.

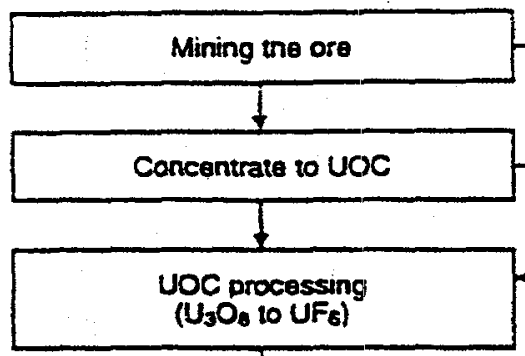

Urantum purehase

$\left(\mathrm{U}_{3} \mathrm{O}_{3}\right.$ 10 UFs)

Converzion

Recoverad uratum

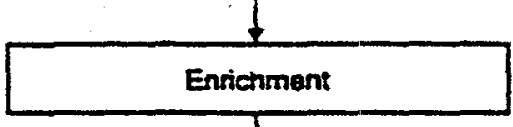

Eardebmant

Fual tabreation

(inctuding conversion to $\mathrm{UO}_{2}$ )

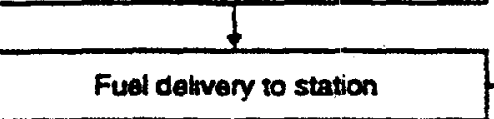

Fabricatlas

Recovered aletonlum

Reactor operation

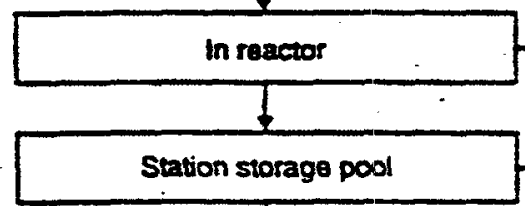

Rezetor oparation
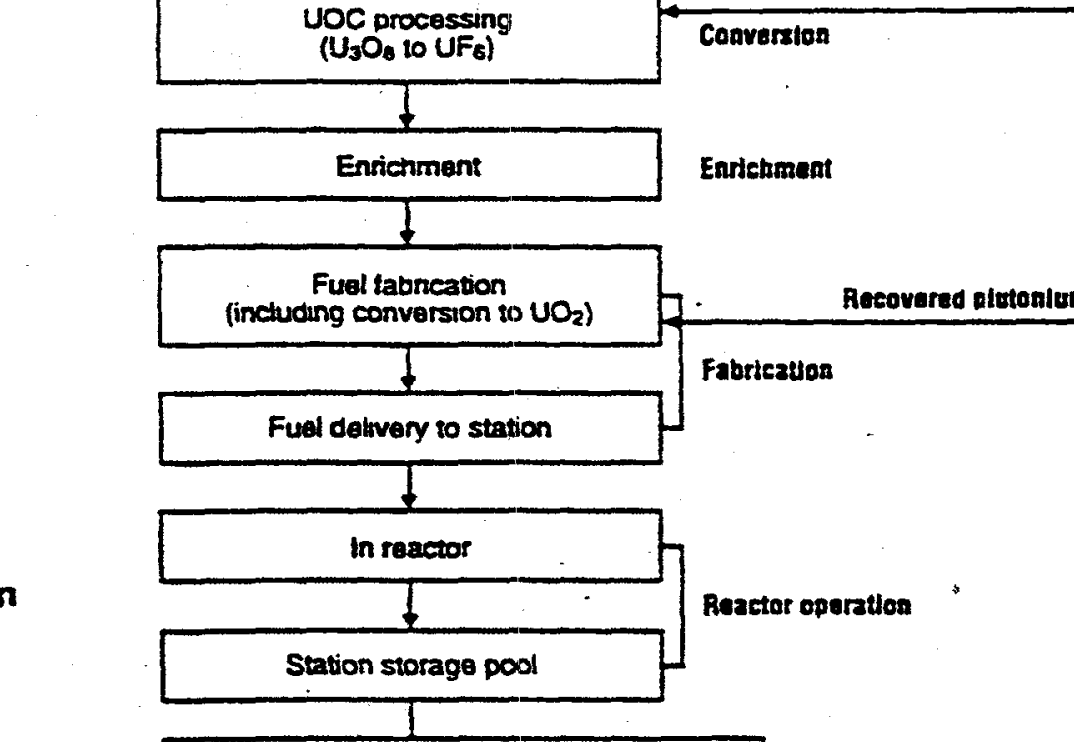
N4-type PWR reactor ${ }^{46}$. This preliminary analysis suggests that reprocessing spent fuel may not become economical until the end of the 21st century. Further research envisioned for the next year of the project aims to examine the validity of this result for less restrictive assumptions that better reflect cost conditions and institutional factors in Russia.

\subsection{The Levelised-Lifetime-Cost Approach}

In order to compare the costs of electricity production for different fuel-cycle options, the levelised-lifetime-cost approach is used in this study. Following this approach, the costs of all fuel-cycle components are recorded over the lifetime of the reactor, $L$, discounted back to a selected base date, $t_{0}$, and added together. These total discounted costs are averaged over the total discounted electricity generation, $E(t)$, to yield the levelised cost, $C$, of the fuel cycle per unit of electricity output.

$$
C=\frac{\sum_{i} \sum_{t=T_{3 z a r t_{i}}}^{t=T_{\text {end }}} \frac{F_{i}(t)}{(1+i)^{\left(t-t_{0}\right)}}}{\sum_{t=t_{0}}^{t=t_{0}+L} \frac{E(t)}{(1+\tau)^{\left(t-t_{0}\right)}}}
$$

where $T_{\text {start }}$ is the starting date of the $i^{\prime}$ th component, $T_{\text {end }}$ is the completion date of $i$ th component process, and $r$ is the discount rate.

The levelised cost can be interpreted as the constant price of electricity, which, if charged over the whole lifetime of the reactor, would allow the investor to exactly break even, i.e. cover all costs and also show the required return on the capital investment employed, which is represented by the specified discount rate,

\footnotetext{
${ }^{46}$ Most of the data is obtained from NEA/OECD, 1994
} 
$r$. The present analysis is focused on the costs of provision and disposal of reactor fuel. For simplicity it is assumed that the construction and operation of the reactor are not significantly affected by the choice of fuel-cycle option, so that capital costs for the reactor as well as operation and maintenance costs can be ignored for the purposes of this analysis.

\subsection{Components of the Nuclear Fuel Cycle}

The front-end of the two nuclear fuel-cycle options examined here, direct disposal and reprocessing, is identical and equals the sum of uranium purchase, conversion, enrichment, and fabrication costs. As far as the back-end is concerned, the direct disposal option comprises transportation, interim storage, encapsulation and final disposal, while the reprocessing option includes transportation, reprocessing, and the disposal of vitrified high-level wastes. In the latter case, credits for recovered fissile fuel must be included in the assessment of overall costs.

1. The cost of the uranium purchase $F_{1}$ is determined by the natural uranium price, $P_{1}$, and the feed total mass of natural uranium, $M_{f}$, and the loss function $f_{1}=\left(1+l_{2}\right)\left(1+l_{3}\right)\left(1+l_{4}\right)$, where $l_{2}, l_{3}$ and $l_{4}$ are the percentages of natural uranium, partly enriched uranium, and fully enriched uranium lost during the conversion, enrichment and fabrication processes, respectively.

$$
F_{1}=M_{f} f_{1} P_{1}(t)
$$


Note, that the mass of natural uranium needed can be calculated from the reactor loading mass, $M_{p}$.

$$
M_{f}=\frac{\left(e_{p}-e_{t}\right)}{\left(e_{f}-e_{t}\right)} M_{p}
$$

Here $e_{p}$ is the fraction of ${ }^{235} U$ charged in the reactor, $e_{t}$ is the fraction of ${ }^{235} U$ in the tails and $e_{f}$ is the fraction of ${ }^{235} \mathrm{U}$ in the uranium feed.

2. The cost of conversion of yellow cake to uranium hexafluoride is

$$
F_{2}=M_{f} f_{1} P_{2}(t)
$$

where $P_{2}(t)$ is the price of conversion per unit mass.

3. The cost of enrichment service $F_{3}$ is determined by the separative work, $S$, required to improve the concentration of ${ }^{235} U$ from $e_{f}$ to $e_{p}$ and the price per unit of separative work, $P_{3}$.

$$
F_{3}=S f_{3} P_{3}(t)
$$

The required amount of separative work units is given by

$$
S=M_{p} V_{p}+\left(M_{f}-M_{p}\right) V_{t}-M_{f} V_{f}
$$

where the value function $V_{x}$ is

$$
V_{x}=\left(2.0 e_{x}-1\right) \ln \left(e_{x} /\left(1.0-e_{x}\right)\right)
$$

where $x$ is the subscript representing $f, p$, or $t$. The loss function $f_{3}$ of this component is $f_{3}=\left(1+l_{3}\right)\left(1+l_{4}\right)$. 
4. The cost of fabricating the enriched ${ }^{235} U$ to serve as directly reactor-usable assembly fuel is

$$
F_{4}=M_{p} f_{4} P_{4}(t)
$$

where $P_{4}$ is the fabrication price and the loss function $f_{4}$ in this stage is $f_{4}=\left(1+l_{4}\right)$.

5. The transportation cost of spent fuel from the reactor site to the reprocessing or interim storage is given by

$$
F_{5}=M_{p} P_{5}(t)
$$

where $P_{5}$ is the transportation price.

6. Depending on whether the reprocessing option or direct disposal option is chosen, the costs for processing spent fuel can be written as

$$
F_{6}=M_{p} P_{6}(t)
$$

For the reprocessing option, $P_{6}$ includes the costs of the actual reprocessing but also the short term interim storage of spent fuel, the vitrification of high level waste (HLW), the conditioning of intermediate-level wastes (ILW) and low-level wastes (LLW), as well as the disposal of ILW and LLW. For the direct disposal option, $P_{6}$ represents the costs of interim storage. Again, all costs are discounted to the time of delivery to the processing site and levelized over all units of spent fuel.

7. The costs for the final disposal of vitrified HLW in the reprocessing option and for the encapsulation and disposal of spent fuel in the direct disposal option 
is

$$
F_{7}=M_{p} P_{7}(t)
$$

where $P_{7}$ is the levelised unit price.

8. The reprocessing option substitutes recovered uranium and plutonium for enriched uranium. To account for this, a certain amount has to be credited towards the total cost of the levelized costs of the reprocessing option.

(a) The uranium credit is

$$
F_{8}=M_{d} f_{8} P_{8}(t)
$$

where the loss function $f_{8}$ is equal to $\left(1-l_{6}\right), M_{d}$ is the mass of discharged uranium, and $P_{8}$ is the value of recovered uranium. The value of recovered uranium is defined as the difference in costs of producing enriched uranium from natural uranium (NU) versus producing it from recovered uranium $(\mathrm{RU})^{47}$.

$P_{8}(t)=\frac{\left(P_{1}(t)+P_{2}(t)\right) \dot{M}_{N U}+P_{3}(t)\left(S_{N U}-S_{R U}\right)-\left(\Delta P_{2}+\Delta P_{3} S_{R U}+\Delta P_{4}\right)}{M_{R U}}$

Here $M_{N U}$ is the mass of natural uranium required for $1 \mathrm{~kg}$ of enriched uranium, $M_{R U}$ is the recovered uranium required for $1 \mathrm{~kg}$ of enriched uranium, $S_{N U}$ is the separative work for $1 \mathrm{~kg}$ of enriched uranium from natural uranium, $S_{R U}$ is the separative work for $1 \mathrm{~kg}$ of enriched uranium from recovered uranium, $\Delta P_{2}$ is the premium for conversion of 1 $\mathrm{kg}$ recovered uranium, $\Delta P_{3}$ is the premium per unit $S_{R U}$ for enrichment

${ }^{47} \mathrm{NEA} / \mathrm{OECD}, 1989$ 
of recovered uranium, and $\Delta P_{4}$ is the premium for the fabrication of fuel from $1 \mathrm{~kg}$ of recovered uranium. The premiums represent additional casts of the reprocessing option which are due to the existence of strong neutron absorbers ${ }^{236} U$ and gamma emitters ${ }^{232} U$ and ${ }^{234} U$ in the spent fuel.

(b) The plutonium credit is given by

$$
F_{9}=M_{P u_{f}} f_{8} P_{9}(t)
$$

where $P_{9}$ is the value of recovered plutonium and $M_{P_{u_{f}}}$ is the mass of fissile plutonium in the spent fuel. The plutonium value is defined as the savings per unit recovered plutonium accruing from using recovered plutonium instead of natural uranium.

$$
P_{9}(t)=\frac{\left(P_{1}(t)+P_{2}(t)\right)\left(M_{N U}-M_{N U}^{\prime}\right)+S_{N U} P_{3}(t)+P_{4}(t)-P_{4}^{M O X}(t)}{M_{P_{u}}}
$$

Here $M_{N U}^{\prime}$ is the mass (in $\mathrm{kg}$ ) of uranium in $1 \mathrm{~kg}$ mixed oxide (MOX), $P_{4}^{M O X}$ is the price of fabrication of MOX fuel, and $M_{P u}$ is the mass (in $\mathrm{kg}$ ) of fissile plutonium required for $1 \mathrm{~kg}$ of MOX fuel.

\subsection{Cost Developments over Time}

Many of the above cost components of the nuclear fuel cycle vary over time, depending on supply and demand conditions, technological progress, changes in safety regulations, etc. Although it is impossible to forecast exact future cost developments, some trends can be predicted, implying that reprocessing will become more 
economical over time.

- Uranium prices have been depressed due to an oversupply in the uranium market. However, with proceeding depletion of uranium reserves, extraction costs will increase, causing prices to rise.

- While the prices of conversion and fuel fabrication have proven relatively stable over the past decade, the cost of separative work can be significantly reduced if new technology, such as laser or improved centrifugal enrichment, is commercialized in the future.

- The costs of reprocessing can also be expected to decrease with growing experience and technological progress. Furthermore, the expansion of the market for reprocessing services could allow plant operators to take advantage of economies of scale.

- Many uncertainties exist about the price for final disposal of vitrified HLW in the reprocessing option since currently no such facility is in operation. Similarly, in the absence of permanent storage facilities there is no reliable cost data for permanent storage in the direct-disposal option.

\subsection{Regional Cost Differences}

In order to make the present results applicable to Russia, it is essential to pay attention to regional differences in fuel-cycle costs, which can be due to geographic characteristics, differences in technology or safety regulations, as well as labor cost 
Table 7. Fuel Cycle Unit Prices

\begin{tabular}{|c|c|c|}
\hline Component & Reference unit price & Sensitivity range \\
\hline Conversion & $\$ 8 / \mathrm{kg} \mathrm{U}$ & $\$ 6-\$ 11 / \mathrm{kg} \mathrm{U}$ \\
Enrichment & $\$ 110 / \mathrm{SWU}$ & $\$ 80-\$ 130 / \mathrm{SWU}$ \\
Fabrication & $\$ 275 / \mathrm{kg} \mathrm{U}$ & $\$ 200-\$ 350 / \mathrm{kg} \mathrm{U}$ \\
Reprocessing option: & & \\
spent fuel transport & $\$ 50 / \mathrm{kg} \mathrm{U}$ & $\$ 20-\$ 80 / \mathrm{kg} \mathrm{U}$ \\
reprocessing & $\$ 720 / \mathrm{kg} \mathrm{U}$ & $\$ 540-\$ 720 / \mathrm{kg} \mathrm{U}$ \\
MOX fuel & $\$ 1100 / \mathrm{kg}$ & $\$ 800-\$ 1400 / \mathrm{kg}$ \\
VHLW disposal & $\$ 90 / \mathrm{kg} \mathrm{U}$ & $\$ 90-\$ 580 / \mathrm{kg} \mathrm{U}$ \\
Direct disposal option: & & \\
spent fuel transport \& storage & $\$ 230 / \mathrm{kg} \mathrm{U}$ & $\$ 60-\$ 290 / \mathrm{kg} \mathrm{U}$ \\
encapsulation \& disposal & $\$ 610 / \mathrm{kg} \mathrm{U}$ & $\$ 140-\$ 670 / \mathrm{kg} \mathrm{U}$ \\
\hline
\end{tabular}

Source: NEA/OECD. 1994.

or purchasing power disparities. The following table illustrates the degree of uncertainty and regional cost differences. The given reference prices in the reprocessing option are based on cost data supplied by British Nuclear Fuels Ltd., which has taken into consideration the latest reprocessing plants of THORP at Sellafield and UP3 at Le Hague. The cited reference prices in the direct disposal option are supplied by Swedish Nuclear Fuel and Waste Management Co. ${ }^{48}$. The sensitivity range shows the extent of cost variations among different countries, unfortunately not including Russia.

According to Table 7, the most significant cost differences exist in the fuel fabrication and over the whole back-end of the fuel cycle. The size of operations and the age of existing plants play important roles in accounting for differences in

\footnotetext{
${ }^{48}$ NEA/OECD. 1994.
} 
fabrication and reprocessing costs. An even larger uncertainty exists with respect to interim storage and final disposal costs. Estimated costs vary among the different countries, due to differences of scale, storage concept, and length of storage period.

\subsection{An Example: Comparison of Fuel Cycle Costs for a PWR}

To illustrate the use of the above "stand-alone" model, the levelised nuclear fuel-cycle costs of the direct disposal and reprocessing options are computed for a reference French N4-type PWR reactor. The thermal output of the reactor is $4020 \mathrm{MW}$, resulting in an electric output of $1390 \mathrm{MW}$. The averaged load factor is assumed to be $75 \%$ over a 30 -year lifetime. The fuel burn-up at equilibrium is $42500 \mathrm{MWd} / \mathrm{t}$. The annual uranium load in the reactor is $28.0 \mathrm{t}$ producing $26.4 \mathrm{t}$ spent fuel with $218.4 \mathrm{~kg}$ fissile plutonium. The fraction of ${ }^{235} \mathrm{U}$ is $0.711 \%$ in the natural uranium yellow cake, $3.6 \%$ in the reactor, and $0.81 \%$ in the spent fuel ${ }^{49}$.

Due to the neutron absorption of ${ }^{236} U$, the fraction of ${ }^{235} U$ charged to the next reactor from the recovered uranium is $4.08 \%$. To produce $1 \mathrm{~kg}$ MOX fuel, $0.044 \mathrm{~kg}$ fissile plutonium and $0.933 \mathrm{~kg}$ natural uranium are needed. The remaining fuel-cycle assumptions are given in Table 8.

Unfortunately, sensitivity ranges for some technical assumptions were not available. Fuel-cycle costs are assumed to equal the reference data from Table 7 and remain constant over time, with the exception of the price of natural uranium. Due to continuing reserve depletion, uranium prices are expected to increase relative to

\footnotetext{
${ }^{49}$ All relevant data was obtained from NEA/OECD, 1994.
} 
Table 8. Fuel Cycle Cost Data

\begin{tabular}{|l|c|c|}
\hline Item & Reference & Sensitivity range \\
\hline Tails assay for enrichment & $0.25 \%$ & $0.20 \%-0.30 \%$ \\
Loss factor for: & & - \\
- conversion & $0.5 \%$ & \\
- fabrication & $1.0 \%$ & \\
- reprocessing & $2.0 \%$ &. \\
Lead time (relative to fuel & & \\
loading date) for: & & \\
- uranium purchase & 24 months & 42 months \\
- conversion & 18 months & 34 months \\
- enrichment & 12 months & 22 months \\
- fábrication & 6 months & 12 months \\
Lag time (relative to spent & & \\
fuel discharge date) for: & & \\
- spent fuel transport & 5 years & \\
reprocessing option & 6 years & \\
- reprocessing & 56 years & \\
- VHLW disposal & & \\
direct disposal option & 5 years & \\
- interim storage & 40 years & \\
- encapsulation \& disposal &
\end{tabular}

Source: NEA/OECD. 1994. 
the costs of other components. More specifically, the price of uranium yellow cake is assumed to increase exponentially according to the following equation, which was estimated based on a set of uranium price and consumption data provided by Chow et al..$^{50}$.

$$
p(t)=11.24 \exp (0.022(t-1992))+9.7
$$

Here $t$ denotes the year for which the price is reported.

The calculation of fuel-cycle costs for the reference case, with a discount rate of $5.0 \%$, commissioning year (reference year) 2000 , and base year 1991, are shown in Table 9. The costs of natural uranium, enrichment, and reprocessing clearly dominate the total levelised PWR fuel-cycle cost. Among them, the purchase of natural uranium accounts for the largest cost ratio, approximately $30 \%$ of total fuel-cycle costs.

Table 9. Levelised PWR Fuel Cycle Costs

\begin{tabular}{|c|c|c|}
\hline Component & direct disposal (mills $/ \mathrm{kWh}$ ) & reprocessing (mills $/ \mathrm{kWh}$ ) \\
\hline Uranium & 1.64 & 1.64 \\
Conversion & 0.16 & 0.16 \\
Enrichment & 1.47 & 1.47 \\
Fabrication & 0.71 & 0.71 \\
Transport/Storage & 0.5 & 0.09 \\
Reprocessing & - & 1.26 \\
Disposal & $0.19-$ & 0.013 \\
U credit & - & 0.043 \\
Pu credit & - & 0.002 \\
Total & 4.68 & 5.31 \\
\hline
\end{tabular}

${ }^{50}$ Chow and Solomon, 1993. 
For the reference case, direct disposal appears as the preferable alternative. In order to examine how this conclusion changes with respect to the chosen base year, we project the levelised nuclear fuel-cycle cost for both options up to 2200 . The assumptions of the reference case remain unchanged over time, with the exception of the natural uranium price. The latter is assumed to increase sharply over time, thus increasing the value of plutonium and uranium credits and improving the competitiveness of the reprocessing option. As shown by Figure 5, direct disposal is slightly cheaper than reprocessing until 2100 and becomes more expensive afterwards.

\section{Policy Questions and Quantitative Analysis}

The purpose of employing a regionally disaggregated global energy model in studies like the present one is to provide important input data for the decision model laid out in the previous section. More specifically, a global energy model is needed to predict the development of the nuclear industry, both in Russia and worldwide, as well as to make probabilistic forecasts for the depletion of uranium reserves and the time path of natural uranium prices. This would allow us to replace the uranium price in equation 2 with a uranium-price estimate grounded in a comprehensive model of global energy markets. A global energy model would also contribute to a better understanding of other cost components. By predicting worldwide developments in the nuclear industry as well as fuel-cycle requirements, it would enable us to take into account possible economies of scale in fuel fabrication, reprocessing, and storage. It would also enable us to analyze the prospects of a global market for fuel- 
Levelised Fuel Cycle Cost Difference between Reprocessing

Option and Direct Disposal Option as a function of Time

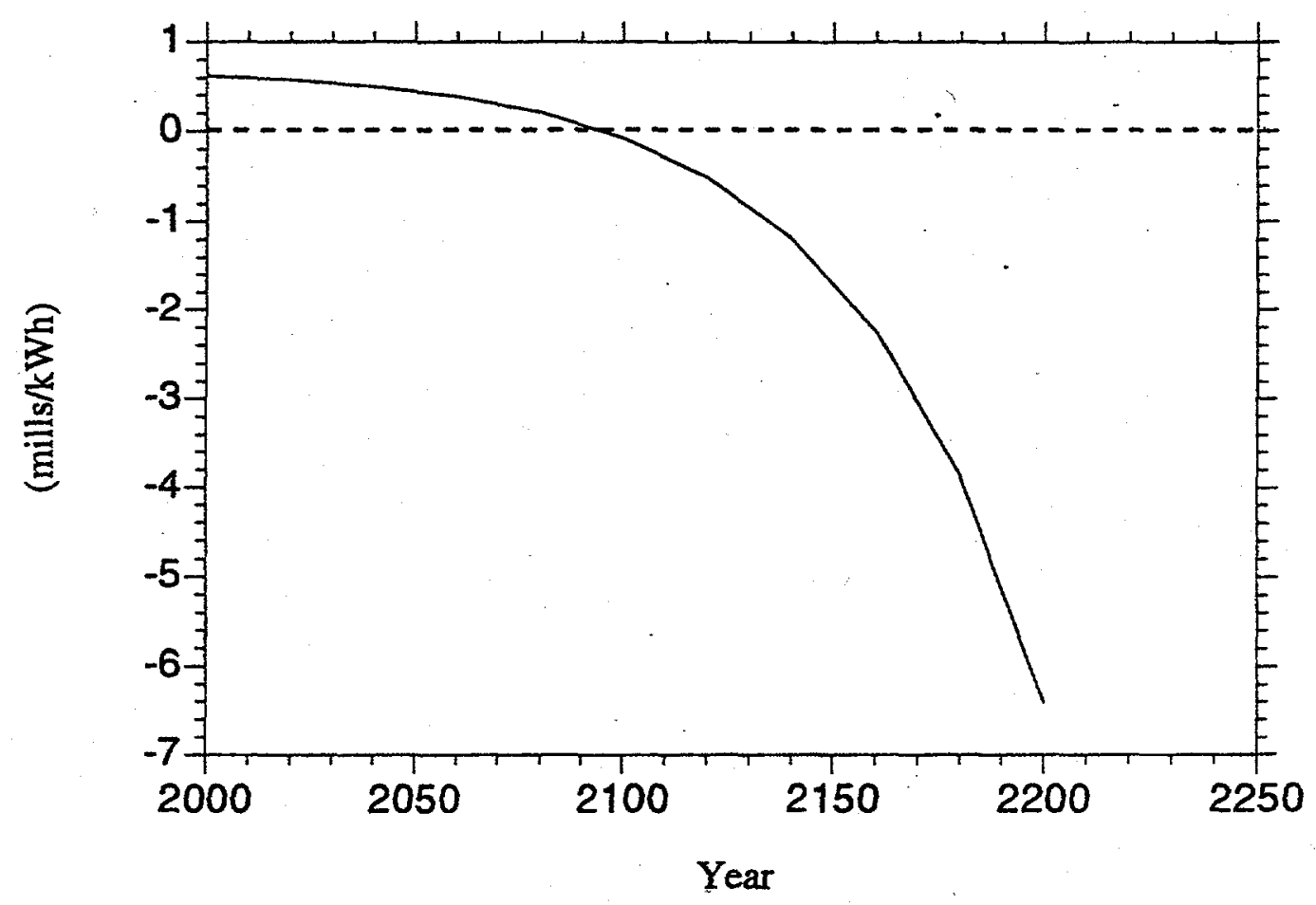

Figure 5: Cost advantage of direct disposal over reprocessing. 
cycle services, especially for reprocessing and storage, which could exploit regional comparative cost advantages and economies of scale. An extensive description of our work on a model particularly appropriate for such a study is given elsewhere ${ }^{51}$. Here we content ourselves with describing policy-related questions it could fruitfully be used to examine.

There is currently a serious mismatch between the plans for the future development of Russia's nuclear industry as promulgated by the Russian Federation Ministry of Atomic Energy (MINATOM) and the funds available for carrying out these plans. Unless and until this changes, neither MINATOMs plans for completing the RT-2 reprocessing facility nor its plans for constructing a new generation of light water and liquid metal cooled commercial power reactors are likely to come to fruition.

There are, however, a number of possible policy-related changes which might be precipitated by Russia and/or other states and could alter the current situation. We are interested in analyzing in greater depth the following seven policy scenarios because we feel that various governments might wish to anticipate and react to them in their energy and security policies toward Russia.

1. Russia allows radwaste from imported spent fuel be stored in Russia indefinitely.

2. Russia allows imported spent fuel to be stored in Russia without reprocessing.

3. Russia gives MINATOM the power to effectively collect outstanding payments

${ }^{51}$ Clifford Singer et al, "Nuclear Fuel Cycle Policies in South Asia." 
and/or set electricity prices.

4. Russia forces her fast spectrum reactors to compete commercially.

5. The public gradually develops greater trust in irradiated fuel management

6. The Eurasian natural gas pipeline network is substantially extended.

7. Russia suffers from severely restricted access to the global uranium market.

Items 1-4 on this list depend primarily on Russian government policy, while items 5 and 6 require an interaction between the policies of Russia and other governments. Item 7 is a concern the Russians explicitly expressabout a possible major policy change by other governments, i.e. detrimenting Russian interests in favor of those of an effective politically and/or economically motivated boycott or uranium cartel. We now briefly discuss each of these points.

\subsection{Funds for Expanding Reprocessing}

The most immediate organizational barrier to expansion of fuel reprocessing capacity in Russia is the lack of a source of funds to complete the RT-2 reprocessing facility. A prospective source of funds is fees from foreign sources of spent fuel. However, current law requires re-export of high level reprocessing waste (radwaste) within twenty years of spent fuel import, rather than indefinite storage of resulting radwaste in Russia. The current situation is evidently not sufficiently attractive on economic and institutional grounds for a large enough commitment of foreign source material to provide a funding base to proceed with RT-2 construction. Changing 
this restriction would allow for additional economies of scale on radwaste storage and could make shipping spent fuel to Russia a more attractive option for some countries which are grappling with the institutional problem of planning a long term future for their own radwaste. In order to better understand the economic incentives for this kind of policy change, it would be useful to quantitatively analyze the material flows which would be necessary to generate at least enough funding to recommence and continue construction of Russian reprocessing facilities.

The other side of this coin is that it, would currently be even cheaper to import radwaste without reprocessing it. Thus, just because a decision is made to allow essentially indefinite retention of imported radwaste, it does not necessarily follow that a durable arrangement will be established to allow the resulting attractive revenue source to be dedicated to completion and operation of an associated reprocessing facility. Especially in an era where the cost of capital is very high, such a revenue source might well be diverted immediately or subsequently to other purposes, either by direct design or by inadequate attention to the prompt construction and operation of a facility which meets the safety and security standards impose upon it. It would be useful to quantitatively examine the net revenue stream which could be made available by storing spent fuel of both domestic and foreign origin for very extended period of time before reprocessing.

\subsection{Reactor Construction}

Under current conditions, MINATOM is supposed to finance new reactors based on revenue streams from selling the power generated in nuclear reactors. However, 
it currently does not set electricity prices, nor does it generally interrupt power supply nor otherwise uniformly force prompt payment for delivery of its product. Even if institutional arrangements evolve to enforce payment by end consumers, there will still remain the question of how consumer prices are set and how much of the resulting revenues the regional distribution authorities are required to remit to the nuclear power generation system. Detailed analysis of various reasonably likely scenarios for changes of the institutional system which controls these revenue flows is essential for fully understanding the possibilities for future evolution of nuclear systems in Russia. It would be useful to quantitatively analyze how the development of the Russian nuclear industry would be affected by establishing full payment for power delivery, establishing a more even system of distributing revenues to suppliers, or by relaxing regionally imposed consumer price controls.

The question of the distribution of reactor types built with a given revenue stream is currently an issue more directly under MINATOM control. Russia has over a decades experience with running a large commercial fast neutron spectrum reactor at reportedly high availability. However, the accounting, operational safety, and security measures that would be applied to future commercial fast reactors are still not fully in place. An analysis of the possible details of these measures in the context of the institutional level at which the commercial competition between light water and liquid metal reactors will be evaluated is also needed for an adequate understanding of the future reactor type mix in Russia. It would be useful to quantitatively examine the consequences for reactor type distribution resulting from different economic institutions, i.e. central planning on this issue under current 
policy, central planning under more economically optimal policy, and competition under a more decentralized decision making system.

\subsection{Public Acceptance}

The evolution of attitudes towards things nuclear in various sectors of the public and in controlling institutions determines the policy choices concerning the above questions. If one accepts the importance of attitudes inherited from an era when the military role of plutonium was dominant, then an examination of possible future evolutions of these attitudes within a post-Cold War framework is also needed. Public and institutional concerns in this regard were originally generated via international confrontation but will subsequently evolve through more or less international cooperation, quite possibly over a very extended period of time. It would be useful to analyze the impact changes in public and institutional attitudes have, primarily by considering a range of different decisions that impact the feasibility or the costs of various choices about the Russian nuclear fuel cycle, inclinding standards for long term handling of radwastes and the costs for nuclear facility construction and operation resulting from safety and security regulation.

\subsection{Regional and Global Energy Markets}

The extension of the Eurasian network of fluid fuel pipelines is a rapidly evolving enterprise which is heavily influenced by public policy ${ }^{52}$. To the very considerable degree that Russia is affected by the construction of this network, two competing

\footnotetext{
${ }^{52}$ Sinyak. 1995.
} 
influences on her nuclear industry can be identified. On one hand, increased opportunities for the export of Russian fossil fuels may accelerate the depletion of its cheaper fuel resources, thus bringing forward the date at which nuclear power becomes competitive with the progressively less attractive fossil fuel deposits that remain. On the other hand, extension of modern natural gas pipelines in Russia and elsewhere could provide stiffer competition for nuclear electricity generation, thereby reducing uranium usage and the economic incentive for plutonium reprocessing. It would be useful to quantitatively examine the impact of various degrees of increasing accessibility of natural gas and its possible impact on the Russian nuclear power system.

As noted above, Russia currently has such large stocks of enriched uranium that it is even subject to temporary export restrictions on anti-dumping grounds. Thus, it may at first seem odd to propose looking at the possible consequences of Russia eventually losing free access to uranium imports. However, the following qualitative chain of reasoning, clearly expressed by Russian contributors to a major international meeting on Nuclear Fuel Cycle and Reactor Strategies this year in Vienna, explains why this is necessary: The break-up of the Soviet Union left Russia with limited uranium supplies. Guaranteeing energy resources will, thus, eventually require construction of fast spectrum reactors. Plutonium made in nuclear reactors will eventually be a valuable source of fuel for fast reactors. Experience with reprocessing and fast reactors will be necessary to prepare for this eventuality. (Similar sentiments were also expressed in reviews of the Western European, Japanese, and Indian programs, with the possibility of the replacement of uranium-233 for 
plutonium in the India case.) As far as it goes, this point of view is qualitatively self-consistent; and it also appears to be deeply imbedded, both institutionally and in the minds of many individuals who influence the formation and implementation of policy. Our experience suggests that trying to expand the qualitative framework of this discussion is unlikely to be very successful for the readily foreseeable future. We, thus, suggest to begin by better defining its quantitative background.

In particular, it would be useful to invite one or more Russian analysts experienced in the analysis of nuclear fuel cycle economics to establish a modest collaborative effort. This effort would begin at the earliest possible date to start writing as detailed as possible a quantitative description of calculations that have been done so far concerning energy futures, with emphasis on their nuclear component. The following questions should be addressed: What is our best present knowledge of global and regional uranium resources as a function of extraction cost? What would be the quantitative consequences of each country's eventually being forced to rely on a sole external uranium exporter, or even losing access to the global uranium market altogether? How would the costs resulting from the continuous experience with reprocessing and/or commercial-scale fast reactor technology compare with the costs of archiving the current experience and restarting these technologies when depletion of cheaper resources eventually drives up the cost of newly mined uranium?

The project was intended to continue work on the joint use of one or more quantitative models of nuclear power economics. With the funding for this project as originally established, such a model was to be developed over the course of two years and then applied to Russian nuclear policy questions formulated in the interim. As 
the project goals were subsequently redefined and the project discontinued after one year, we include for possible future reference a footnote to a report which describes the detailed development of a suitable economic optimization model. ${ }^{53}$

While it is useful for analysts in the U.S. and other countries to have as complete an understanding of Russian nuclear power and fuel cycles as possible, it should be obvious that what are most critical are the perspectives developed by Russians themselves. Despite the formidable intellectual capital which their country possesses, the sustained development and application of state-of-the-art software and database packages needed for a comprehensive attack on the types of problems discussed above is a daunting challenge under present conditions in many Russian research institutions without the availability of a well-functioning international collaboration. In-depth perspectives on the likelihood of the type of-scenario shown above in Figure 2 and various alternatives to it are essential to a thorough understanding of the likely future commercial uses of plutonium in Russia, and therefore to appropriate current approaches to managing fissile materials. Pursuit of cost-effective means of developing such collaboration would, thus, be desirable, and indeed it is arguably essential to develop a more broadly shared and constructive point of view on nuclear power issues.

\section{Conclusions}

Although any conclusions about the prospects of spent-fuel reprocessing in Russia are necessarily tentative given the modest scale of the present research project, a few

\footnotetext{
${ }^{53}$ Clifford Singer et al, "Nuclear Fuel Cycle Policies in South Asia."
} 
remarks can be made. Applying our levelized-cost decision model to a generic set of PWR reference data suggests that direct disposal may be economically superior to reprocessing until well into the next century, but could prove to be more expensive thereafter. However, this result relies on a number of assumptions, especially about the price of natural uranium, MOX-fuel fabrication, and reprocessing. Higher uranium prices, caused by a rapid increase in worldwide nuclear capacity, or reduced costs for reprocessing and MOX-fuel fabrication could make continuous maintenance or at least earlier re-introduction of the reprocessing option more attractive.

Efforts to tailor an assessment of reprocessing to the specific Russian situation require accomplishment of a number of tasks.

1. A fundamental task is to use Russia-specific data in the calculation. Unfortunately, cost data for Russia's nuclear industry is not readily available, so that an extensive literature and conversational search for additional information is needed. Moreover, it is necessary to use cost information from other countries to estimate the costs for components of Russia's nuclear program based on technical, geographical, and economic characteristics. In addition to the use of MOX-fuel in a LWR, the model has to be expanded to cover the economics of Russia's fast breeder reactors as well.

2. The price of natural uranium plays a crucial role in determining the point in time when reprocessing can become economically competitive with direct disposal. In order to better predict the time path of world prices for natural uranium a global energy model is being developed. The model is designed 
to incorporate interfuel competition in Russia's energy markets as well as the possibility for international trade in fuels and energy products. This work is continuing, as it is also needed for our coordinate studies of global influences on South Asian nuclear policy. Based on this, we expect to obtain significantly better predictions about the future development of nuclear power, the depletion of natural uranium reserves, and the future prices of natural uranium.

3. We recognize that Russia's energy policy cannot be completely understood as the straightforward implementation of least-cost solutions. At least in the short and intermediate-run, perhaps well into the next century, there are a number of background factors which effectively constrain Russia's energy choices. Even if nuclear power proves to be cheaper than its fossil-fuel competitors, a large-scale expansion of nuclear power cannot be expected before 2010. This is due to financial difficulties in the nuclear sector, the expected retirement of $50 \%$ of current capacity, lead times in construction of 5-10 years, and the need to gradually regain the people's confidence in nuclear power after the catastrophe in Chernobyl.

On the other hand, even if nuclear power turns out to be more expensive than fossil-fuel plants, the addition of new plants may be slowed, but it is unlikely that a sudden drop in nuclear power generation would occur. Concerns about employment in the nuclear sector, the inability to shift employment from the nuclear sector to the non-nuclear sector, and the prospects of nuclear technology in the export market are going to bolster interest and support for the nuclear industry, so that nuclear generating capacity is unlikely to decline 
drastically for some time to come.

Finally, we cannot expect Russia to give up reprocessing easily, even if it appears not to be competitive with long term interim storage of the direct disposal of spent fuel. The fact that reprocessing is one of the few high-tech fields where Russia is among the world leaders, pre-existing investments in reprocessing facilities, and the apparent export potential of reprocessing services are likely to generate a commitment to spent-fuel recycling at least in the intermediate run. The completion and commissioning of the RT-2 reprocessing plant at Krasnoyarsk would as a fait accompli further lock Russia into her reprocessing policy. On the other hand, the beginning of final disposal for spent fuel from Russia's RBMK reactors, for which reprocessing is considered not to be economically viable, could signify a new stage in. Russia's nuclear policy where more consideration is given to the direct disposal option.

The effects of current institutional issues are naturally most relevant in the short and intermediate run. As time progresses, institutional problems are likely to be resolved or at least subject to change. We thus envision the impact of idiosyncratic institutional factors to become less predictable in the long run, and treat nominal decisions in the distant future as determined by physically constrained least-cost considerations. As far as nearer-term decisions are concerned, we suggest implementing effects of additional institutional factors in the following two ways. First, we understand that the current status quo and institutional factors constrain energy choices. As a result, they put bounds on certain policy variables, for example, the share of nuclear power or 
the growth rate of nuclear capacity. Second, we recognize that institutional factors often pose a relative rather than an absolute barrier to policy decisions. However, the impact of current background factors declines over time, so that the size of the cost premiums has to decrease and eventually approach zero for the distant future. For these reasons and those presented in the previous section of this report, we suggest that continuing cooperative efforts at quantitative analysis of Russian nuclear fuel cycle decisions could prove well worth while. 


\section{References}

[1] B. Chow and K. Solomon, Limiting the Spread of Weapon-Usable Fissile Materials, National Defense Research Institute, 1993.

[2] CIA. Soviet Energy Data Resource Handbook, SOV 90-10021, May 1990.

[3] Dienes, Leslie et al. Energy and Economic Reform in the Former Soviet Union, 1994.

[4] EIA/DOE. World Nuclear Outlook 1995, Washington, D.C. 1995.

[5] Ebel, Robert E. Energy Choices in Russia, The Center for Strategic and International Studies, Washington, D.C. 1995.

[6] Edmonds, Jae and John M. Reilly. Global Energy: Assessing the Future, Oxford University Press 1985.

[7] Interagency Commission for the Co-ordination of the Programme Development. Energy Strategy of Russia (Major Provisions), in IEA/OECD. 1995, p.269-312.

[8] IEA/OECD. Electricity in European Economies in Transition, Paris 1994.

[9] IEA/OECD. Energy Policies of the Russian Federation: 1995 Survey, Paris, France 1995.

[10] IEA/OECD. Russian Energy Prices, Taxes and Costs 1993, Paris 1994.

[11] Interfax. Ecologists Urge to Annul Yeltsin Decree Allowing Import of Radioactive Wastes to Russia, February 2, 1995. 
[12] International Nuclear Safety Center (INSC) Database (ANL/USDOE).

[13] NEA/OECD. The Economics of the Nuclear Fuel Cycle, Paris, France 1994.

[14] NEA and IEA/OECD. Projected Costs of Generating Electricity: Update 1992, Paris 1993.

[15] NEA/OECD. Plutonium Fuel - An Assessment, Paris, France 1989.

[16] NEI. Soviet-Designed Nuclear Power Plants in Russia, Ukraine, Lithuania, the Czech Republic, the Slovak Republic, Hungary and Bulgaria, Nuclear Energy Institute Source Book, Third Edition, Washington DC, 1995.

[17] Pearson, V. and J.Nadler, Overview of Spent Nuclear Fuel Management in the Former Soviet Union - Part II, U.S. DOE Report, 1996.

[18] Maubacq, F. and C. Tailland, Les Centrale Nucleaires dans le Monde, 1997, Commissariat a l'Energie Atomique (1997).

[19] PlanEcon. Russian Economic Monitor; PlanEcon Report, 1997, Volume 13, No.3-4.

[20] Reuter. Russia Ready to Process Foreign Nuclear Waste, September 5, 1995.

[21] Russian Academy of Sciences The Concept of New Politics in Power Production in Russia, Moscow, May 1992.

[22] Singer, Clifford E. Global Energy and Fuel Cycle Models, manuscript, 1996.

[23] Singer, Cliford E., Madhu Khanna, Sam Addy, Ji Qiang, Jurgen Wiesmann, and Junli Zhang, "Nuclear Fuel Cycle Policies in South Asia," October 13, 
1997, University of Illinois at Urbana-Champaign Program on Arms Control, Disarmament, and International Security report to U.S. Department of Energy.

[24] Sinyak, Y. "Nuclear Energy in Eastern Europe and the Former Soviet Union: How Safe and How Much?," Energy and Environment, Vo. 6, 1995, p. 337, gives an informative review of trade-offs between gas-fired and nuclear electricity plant construction.

[25] Skolnikoff, Suzuki, and Oye, International Responses to Japanese Plutonium Programs, Working Paper, Center for International Studies, Massachusetts Institute of Technology, August 1995.

[26] World Bank. States of the Former USSR, Statistical Handbook 1993, Washington DC, 1993. 
Appendix 1. Operating Nuclear Power Stations

\begin{tabular}{|c|c|c|c|c|c|c|c|}
\hline Site & Reactor Unit & Type & Model & $\begin{array}{c}\text { Capacity } \\
\text { (MWe Net) }\end{array}$ & $\begin{array}{c}\text { Capacity } \\
\text { (MWe Gross) }\end{array}$ & Construction & Planned Retirement Date \\
\hline \multirow[t]{4}{*}{ Balakovo } & 1 & VVER & $\mathrm{B}-320$ & 950 & 1000 & 1980 & \\
\hline & 2 & VVER & B-320 & 950 & 1000 & 1981 & \\
\hline & 3 & VVER & B-320 & 950 & 1000 & 1982 & \\
\hline & 4 & VVER & B-320 & 950 & 1000 & 1984 & \\
\hline Beloyarsk & 3 & FBR & BN-600 & 560 & 600 & 1969 & 2010 \\
\hline \multirow[t]{4}{*}{ Bilibino } & 1 & GBVVR & BN-600 & 11 & 12 & 1970 & 2004 \\
\hline & 2 & GBVVR & EGP-6 & 11 & 12 & 1970 & 2004 \\
\hline & 3 & GBVVR & EGP-6 & 11 & 12 & 1970 & 2005 \\
\hline & 4 & GBVVR & EGP-6 & 11 & 12 & 1970 & 2006 \\
\hline \multirow[t]{2}{*}{ Kalinin } & 1 & VVER & EGP-6 & 950 & 1000 & 1977 & \\
\hline & 2 & VVER & V-338 & 950 & 1000 & 1982 & \\
\hline \multirow[t]{4}{*}{ Kola } & 1 & VVER & V-338 & 411 & 440 & 1970 & 2003 \\
\hline & 2 & VVER & V-230 & 411 & 440 & 1973 & 2004 \\
\hline & 3 & VVER & $V-230$ & 411 & 440 & 1977 & 2001 \\
\hline & 4 & VVER & $V-213$ & 411 & 440 & 1976 & 2002 \\
\hline \multirow[t]{4}{*}{ Kursk } & 1 & LWGR & $\mathrm{V}-213$ & 925 & 1000 & 1972 & 2006 \\
\hline & 2 & LWGR & RBMK-1000 & 925 & 1000 & 1973 & \\
\hline & 3 & LWGR & RBMK-1000 & 925 & 1000 & 1978 & \\
\hline & 4 & LWGR & RBMK-1000 & 925 & 1000 & 1981 & \\
\hline \multirow[t]{4}{*}{ Leningrad } & 1 & LWGR & RBMK-1000 & 925 & 1000 & 1970 & 2003 \\
\hline & 2 & LWGR & RBMK-1000 & 925 & 1000 & 1970 & 2005 \\
\hline & 3 & LWGR & RBMK-1000 & 925 & 1000 & 1973 & 2009 \\
\hline & 4 & LWGR & RBMK-1000 & 925 & 1000 & 1975 & \\
\hline Novovoronezh & 3 & VVER & V-179 & 385 & 417 & 1967 & 2001 \\
\hline \multirow[t]{2}{*}{1} & 4 & VVER & V-179 & 385 & 417 & 1967 & 2002 \\
\hline & 5 & VVER & $V-187$ & 950 & 1000 & 1974 & 2010 \\
\hline \multirow[t]{3}{*}{ Smolsnk } & 1 & LWGR & FBMK-1000 & 925 & 1000 & 1975 & \\
\hline & 2 & LWGR & RBMK-1000 & 925 & 1000 & 1976 & \\
\hline & 3 & LWGR & RBMK-1000 & 925 & 1000 & 1984 & \\
\hline Totals & 29 & & & 18,893 & 20,242 & & \\
\hline
\end{tabular}

Source: IEA/OECD, 1995, p. 243. 
Appendix 2. Nuclear Fuel Cycle Facilities of the Former Soviet Union

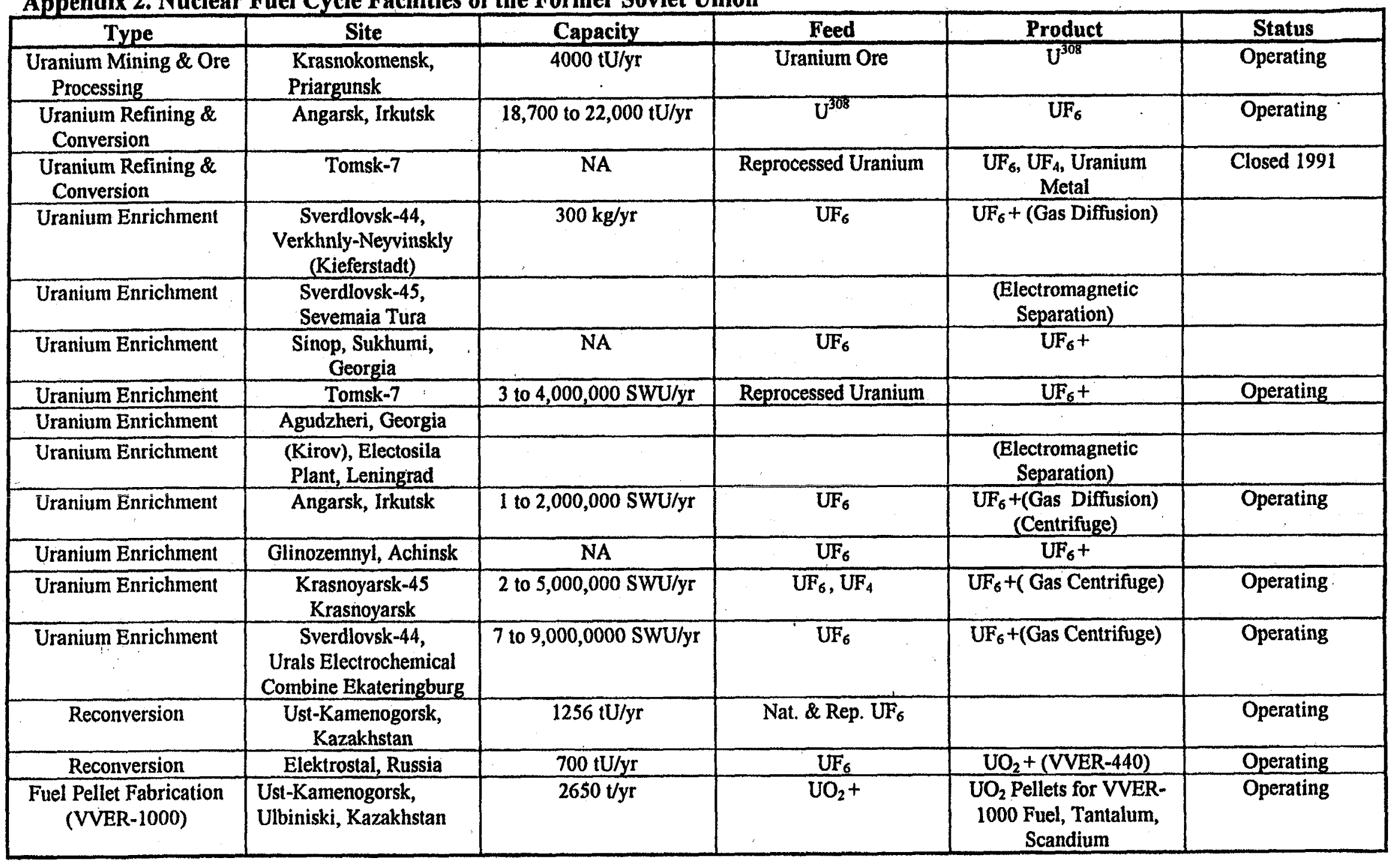




\begin{tabular}{|c|c|c|c|c|c|}
\hline $\begin{array}{l}\text { Fuel Pellet Fabrication } \\
\text { (RBMK) }\end{array}$ & $\begin{array}{l}\text { Ust-Kamenogorsk, } \\
\text { Ulbiniski, Kazakhstan }\end{array}$ & & $\mathrm{UO}_{2}+$ & $\begin{array}{c}\mathrm{UO}_{2}+\text { Pellets for } \\
\mathrm{RBMK} \text {, Tantalum, } \\
\text { Scandium } \\
\end{array}$ & Operating \\
\hline $\begin{array}{l}\text { Fuel Pellet Fabrication } \\
\text { (VVER-440) }\end{array}$ & $\begin{array}{l}\text { Ust-Kamenogorsk; } \\
\text { Ulbiniski, Kazakhstan }\end{array}$ & $700 \mathrm{tU} / \mathrm{yr}$ & $\mathrm{UO}_{2}+$ & $\begin{array}{c}\mathrm{UO}_{2}+\text { Pellets for } \\
\text { VVER-440, Tantalum, } \\
\text { Scandium } \\
\end{array}$ & Operating \\
\hline Beryllium Metal & $\begin{array}{c}\text { Zabaikalsky \& Orel } \\
\text { Enterprises }\end{array}$ & & Ore & Beryllium Metal & Operating \\
\hline Beryllium Products & $\begin{array}{l}\text { Ulbinsky Metallurgical } \\
\text { Plant, Ust-Kamenogorsk }\end{array}$ & & Beryllium Metal & & Operating \\
\hline Lithium Metal & $\begin{array}{l}\text { Novosibirsk Chemical } \\
\text { Concentration Plant }\end{array}$ & & & & Operating \\
\hline Heavy water & $\begin{array}{c}\text { Dneprodzerchinsk, } \\
\text { Ukraine }\end{array}$ & & Water & $\mathrm{D}_{2} \mathrm{O}$ & Operating \\
\hline Heavy water & $\begin{array}{l}\text { Chirchik Nitrogen *. } \\
\text { Combine, Chirchik }\end{array}$ & $\cdots$ & Water & $\mathrm{D}_{2} \mathrm{O}$ & \\
\hline $\begin{array}{l}\text { Zirconium Tubing } \\
\text { Production }\end{array}$ & Glazov, Udmirtia & $6000 \mathrm{~km} / \mathrm{yr}(2000 \mathrm{t} / \mathrm{yr})$ & Zirconium Ore & $\begin{array}{c}\text { VVER Fuel Assembly } \\
\text { Tubing } \\
\end{array}$ & Operating \\
\hline $\begin{array}{c}\text { Fuel Assembly } \\
\text { Fabrication (VVER, } \\
\text { BWR) } \\
\end{array}$ & Atommash & $700 \mathrm{tHM} / \mathrm{yr}$ & $\mathrm{UO}_{2}+$ Pellets & $\begin{array}{l}\text { BWR \& VVER } \\
\text { Assemblies }\end{array}$ & \\
\hline $\begin{array}{c}\text { Fuel Assembly } \\
\text { Fabrication (VVER-440) }\end{array}$ & $\begin{array}{c}\begin{array}{c}\text { Elektrostal, Moscow } \\
\text { Region }\end{array} \\
\end{array}$ & $700 \mathrm{t} / \mathrm{yr}$ & $\mathrm{UO}_{2}+$ Pellets & $\begin{array}{c}\text { VVER-440 Fuel } \\
\text { Assemblies }\end{array}$ & Operating \\
\hline $\begin{array}{c}\text { Fuel Assembly } \\
\text { Fabrication (VVER- } \\
1000 \text { ) } \\
\end{array}$ & $\begin{array}{c}\text { Chemical Concentrates } \\
\text { Plant, Novosibirsk, } \\
\text { Siberia } \\
\end{array}$ & $1000 \mathrm{t} / \mathrm{yr}$ & $\mathrm{UO}_{2}+$ Pellets & $\begin{array}{l}\text { VVER-1000 Fuel } \\
\text { Assemblies }\end{array}$ & Operating \\
\hline $\begin{array}{c}\text { Fuel Assembly } \\
\text { Fabrication (RBMK) }\end{array}$ & $\begin{array}{c}\begin{array}{c}\text { Elektrostal, Moscow } \\
\text { Region }\end{array} \\
\end{array}$ & $570 \mathrm{t} / \mathrm{yr}$ & $\mathrm{UO}_{2}+$ Pellets & RBMK Fuel Assemblies & Operating \\
\hline $\begin{array}{c}\text { Fuel Assembly } \\
\text { Fabrication (FBR) }\end{array}$ & $\begin{array}{c}\text { Elektrostal, Moscow } \\
\text { Region }\end{array}$ & $20 \mathrm{t} / \mathrm{yr}$ & $\mathrm{UO}_{2}+$ Pellets & $\begin{array}{c}\text { BN-350 \& } 600 \text { Fuel } \\
\text { Assemblies }\end{array}$ & Operating \\
\hline $\begin{array}{c}\text { Fuel Assembly } \\
\text { Fabrication (FBR } \\
\text { Blanket) } \\
\end{array}$ & $\begin{array}{c}\text { Elektrostal, Moscow } \\
\text { Region }\end{array}$ & $15 \mathrm{t} / \mathrm{yr}$ & $\mathrm{UO}_{2}+$ Pellets & $\begin{array}{l}\text { BN-350 \& } 600 \text { Fuel } \\
\text { Blanket Assemblies }\end{array}$ & Operating \\
\hline Fuel Assembly & Mayak Paket Site, & $300 \mathrm{~kg} / \mathrm{yr}(10-12 \mathrm{FAs})$ & MOX & BN-600, BN 350 FBR & Operating \\
\hline
\end{tabular}




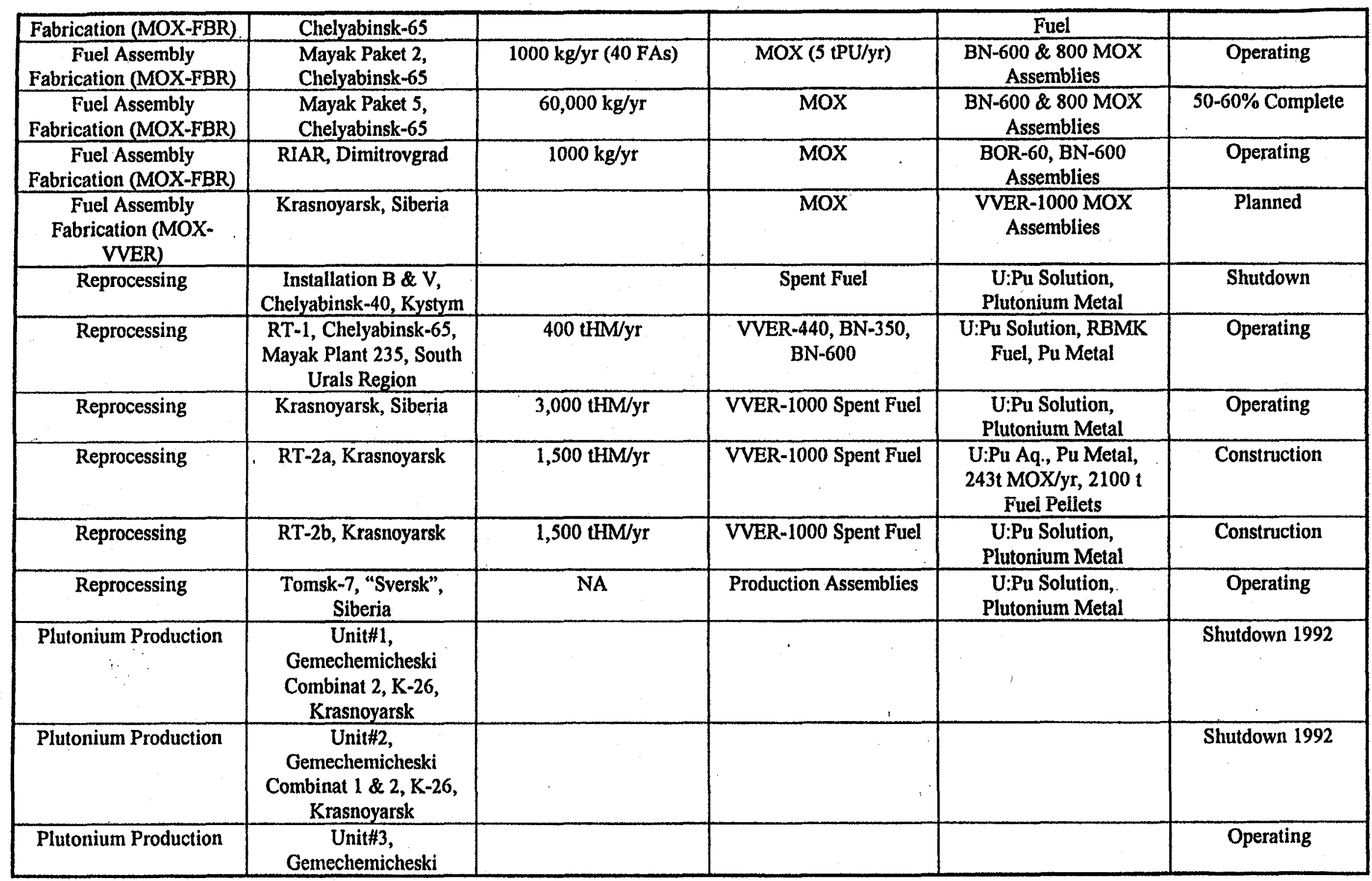




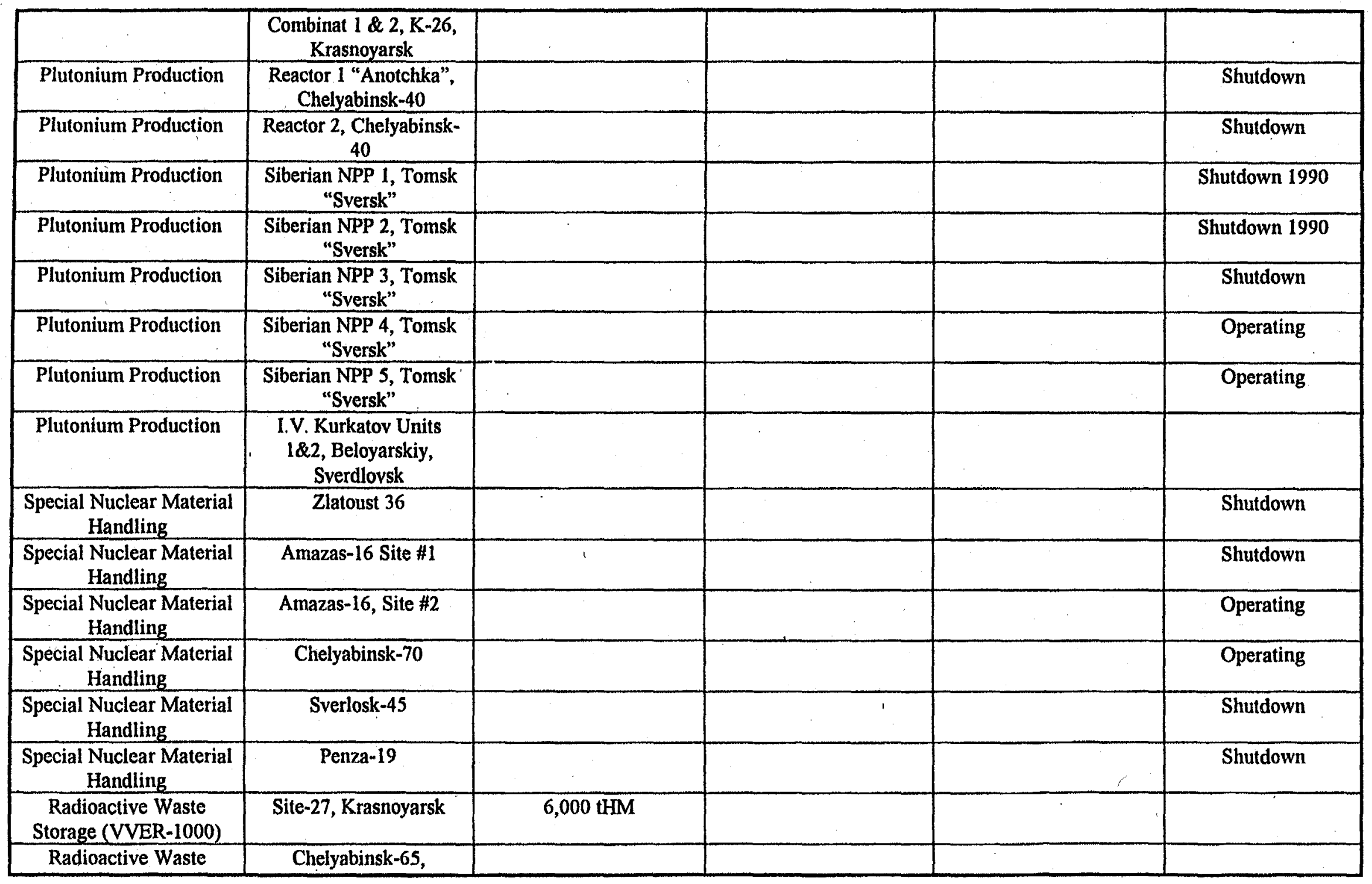




\begin{tabular}{|c|c|c|c|c|c|}
\hline Storage (VVER-440) & Chelyabinsk & & & & \\
\hline $\begin{array}{l}\text { Radioactive Waste } \\
\text { Storage (RBMK) }\end{array}$ & $\begin{array}{l}\text { Leningrad, Kursk, } \\
\text { Smolensk NPP sites }\end{array}$ & 2,000 t/site & & & \\
\hline HLW Vitrification & $\begin{array}{c}\text { Mayak Site, } \\
\text { Chelyabinsk, South } \\
\text { Urals }\end{array}$ & 500 cubic meters/yr & Hi-Level Waste & Glass Blocks & Closed 1988 \\
\hline HLW Vitrification & $\begin{array}{c}\text { Mayak Plant 235, } \\
\text { Chelyabinsk, South } \\
\text { Urals }\end{array}$ & 500 liters/hr & Hi-Level Waste & Phosphate Glass & Operating \\
\hline $\begin{array}{l}\text { HLW Disposal (Liquid } \\
\text { Injection) }\end{array}$ & $\begin{array}{l}\text { Siberian Chemical } \\
\text { Combine, Tomsk-7 }\end{array}$ & $400 \mathrm{MCI}$ Injected & & & \\
\hline $\begin{array}{l}\text { HLW Disposal (Liquid } \\
\text { Injection) }\end{array}$ & $\begin{array}{l}\text { Mining and Chemical } \\
\text { Combine, Krasnoyarsk- } \\
26\end{array}$ & 500 MCI Injected & & & \\
\hline $\begin{array}{l}\text { HLW Disposal (Liquid } \\
\text { Injection) }\end{array}$ & NIAR, Dimitrovgrad & & & & \\
\hline $\begin{array}{l}\text { HLW+LLW Disposal } \\
\text { (Sea Bed) Novoya }\end{array}$ & $\begin{array}{l}\text { Zemlya (Several Sites } \\
\text { off East Coast) }\end{array}$ & 1000 Containers & & & \\
\hline
\end{tabular}

Source: IEA/OECD, 1995, p. 246-247. 